\title{
Hyperresolution Hydrologic Modeling in a Regional Watershed and its Interpretation using Empirical Orthogonal Functions
}

Giuseppe Mascaro ${ }^{1,2}$, Enrique R. Vivoni ${ }^{1,3}$ and Luis A. Méndez-Barroso ${ }^{3,4}$

2. Julie Ann Wrigley Global Institute of Sustainability Arizona State University

Tempe, AZ, USA

3. School of Earth and Space Exploration

Arizona State University

Tempe, AZ, USA

4. Departamento de Ciencias del Agua y Medio Ambiente, Instituto Tecnólogico de Sonora, Ciudad Obregón, Sonora, México

Revised version submitted to Advances in Water Resources May 22, 2015

Corresponding author address: Dr. Giuseppe Mascaro, School of Sustainable Engineering and the Built Environment, Arizona State University, ISTB4, Building 75, Room 778b, Tempe, AZ 85287-6004.E-mail: gmascaro@asu.edu. 
 \\ Abstract}

Hyperresolution $(<1 \mathrm{~km})$ hydrologic modeling of regional watersheds is expected to support a broad range of terrestrial water cycle studies, but its feasibility is still challenging due to process, data and computational constraints, as well as difficulties in interpreting the highdimensional dataset of spatiotemporal model forcings and outputs. We address some of these modeling challenges by extending the application of a physically-based, distributed hydrologic model to the Río San Miguel watershed $\left(3796 \mathrm{~km}^{2}\right)$ in Mexico based on prior efforts that demonstrated the process fidelity at smaller spatiotemporal scales. Long-term (seven year)

simulations are conducted at a hyperresolution $(\sim 78 \mathrm{~m})$ over the large domain using parallel simulation capabilities. To address data sparseness, we develop strategies to integrate ground,

remotely-sensed and reanalysis data for setting up, forcing and parameterizing the model. Complementary tests with observations at individual stations and remotely-sensed spatial patterns reveal a robust model performance. After building confidence in the model, we interpret the spatiotemporal model forcings and outputs using Empirical Orthogonal Functions (EOFs) analyses. For all model outputs, a large portion (58\% to $80 \%)$ of the spatiotemporal variability can be explained by two dominant EOFs, which are related to model forcings and basin properties. Terrain controls on soil water accumulation have a marked impact on the spatial distribution of most hydrologic variables during the wet season. In addition, soil properties affect soil moisture patterns, while vegetation and elevation distributions influence evapotranspiration and runoff fields. Given the large outputs from long-term hyperresolution simulations, EOF analyses provide a promising avenue for extracting meaningful hydrologic information within complex, regional watersheds.

Keywords: distributed hydrologic model, catchment hydrology, North American monsoon, principal component analysis, high performance computing. 


\section{1. Introduction}

3 cycle and its spatiotemporal variability in large domains. For example, DHMs provide support

4 for assessments of water availability, sustainability and security [Döll et al., 2003; Schewe et al.,

5 2014], management of agriculture and land use to assure food security [Schuol et al., 2008;

6 Trabucco et al., 2008; Huang and $L i, 2010]$ and prediction of hydrologic extremes, including

7 floods and droughts [Wood et al., 2002; Lehner et al., 2006; Pappenberger et al., 2011; Forzieri

8 et al., 2014]. Taking advantage of the continuously increasing resolution, frequency and

9 availability of remotely-sensed observations, the applications of DHMs are expected to grow in

10 the context of climate change impacts and increasing water demands [Vörösmarty et al., 2000;

11 Alcamo et al., 2007]. DHMs are also used to provide initial conditions to weather prediction

12 models [e.g., Seuffert et al., 2002], to quantify the effects of climate model forcings at the land

13 surface [e.g., Sulis et al., 2011] and to set hydrologic feedbacks for models of vegetation

14 dynamics [e.g., Ivanov et al., 2008; Maneta and Silverman, 2013]. Furthermore, DHMs allow

15 advancing the basic knowledge of hydrologic processes, including the identification of dominant

16 spatiotemporal patterns and their physical controls across different climatic regimes [Li et al., 17 2005; Vivoni, 2012a; Shen et al., 2013].

18 Recently, Wood et al. [2011] called the hydrologic community to increase the spatial 19 resolution of DHMs up to hyperresolutions of $\sim 1 \mathrm{~km}$ at global scales and $\sim 100 \mathrm{~m}$ at regional and 20 continental scales $\left(10^{3}-10^{6} \mathrm{~km}^{2}\right)$. By capturing the spatial variability of land surface properties 21 with a greater detail, hyperresolution simulations have the potential to improve the representation 22 of hydrologic dynamics in the terrestrial water cycle. To be effective, however, hyperresolution 23 simulations require process models with a relatively high fidelity, but computational constraints 
1 and limited data availability, resolution and coverage have usually prevented their application in

2 large domains. For example, DHMs are typically used at a spatial resolution of 50-100 km at

3 global scales [e.g. Schewe et al., 2014] and at 1-10 km resolution in regional and continental

4 watersheds [e.g., Cai et al., 2014; Liu et al., 2013a; Shen et al., 2013]. As a result of this coarse

5 resolution, physical processes are often highly conceptualized and lateral water transfer in the

6 subsurface may be neglected. For higher resolution applications, a different class of DHMs is

7 able to represent hydrologic processes with a higher fidelity, including surface and subsurface

8 flows in two or three dimensions and the coupled feedbacks between water and energy fluxes

9 [e.g., Ivanov et al., 2004a; Rigon et al., 2006; Ebel et al., 2009; Camporese et al., 2010; Maxwell

10 et al., 2014]. While these models have ideal characteristics for hyperresolution simulations, their

11 computational burden has typically limited their application to small and medium (less than $10^{3}$

$12 \mathrm{~km}^{2}$ ) catchments [e.g., Kollet and Maxwell, 2008; Bertoldi et al., 2010; Sulis et al., 2010;

13 Mascaro et al., 2013; Xiang et al., 2014; Camporese et al., 2014; 2015].

14 Thus, the feasibility of hyperresolution modeling of large watersheds requires addressing

15 several challenges due to tradeoffs between hydrologic process complexity and fidelity, the

16 availability and quality of data needed for model forcing and testing, and the computational

17 resources to conduct the simulations within reasonable time frames. A first challenge is

18 improving the model physics used for terrestrial water cycle dynamics, including enhancing the

19 capability to simulate surface-subsurface interactions and land-atmosphere feedbacks, among

20 other components [Wood et al., 2011]. A second difficult task is calibrating, testing and creating

21 the forcings for hyperresolution DHMs applied over regional watersheds where limited ground

22 observations might be available. Strategies are required to (i) transfer information derived from

23 limited observations at individual sites over larger areas, (ii) evaluate the model ability to capture 
1 spatial patterns of the hydrologic response [Grayson et al., 2002] and (iii) create distributed

2 forcings by integrating available ground data with other sources such as reanalysis products [e.g.,

3 Mitchell et al., 2004; Hamlet and Lettenmaier, 2005]. A third challenge for hyperresolution

4 modeling is meeting the computational demands of representing vast amounts of model data

5 through the use of high performance computing clusters [e.g., Kollet et al., 2010; Vivoni et al.,

6 2011; Liu et al., 2013b].

7 In addition to difficulties related to computational, model structure, and data limitations,

8 another crucial challenge is the manipulation, interpretation and visualization of the high-

9 dimensional, non-linear datasets generated by hyperresolution simulations. As a result, there is a

10 need to design or adapt tools that facilitate these tasks. In climate and atmospheric sciences, the

11 Empirical Orthogonal Function (EOF) analysis is a powerful method extensively used to analyze

12 large spatiotemporal model outputs [Hannachi et al., 2007]. This technique is then extremely

13 suitable to interpret large hydrologic datasets, as it allows (i) capturing the dominant patterns that

14 explain most of the spatial variability, (ii) comparing these patterns with other high-resolution

15 spatial fields including basin properties and atmospheric forcings, and (iii) tracking how the

16 weight of these patterns evolve in time. While previous studies have used EOF analysis to

17 explore rainfall [Espinoza Villar, 2009], soil moisture [Kim and Barros, 2002; Jawson and

18 Niemann, 2007] and streamflow data [Gochis et al., 2006], as well as outputs of coarse

19 resolution models [Liu, 2003; Syed et al., 2004; Schmidt et al., 2008], this technique has not been

20 applied to hyperresolution hydrologic simulations.

21 In this study, we explore the feasibility of long-term hyperresolution simulations in a

22 regional watershed, the Río San Miguel (RSM) in northwest Mexico, using a physically-based

23 DHM known as the TIN-based Real-Time Integrated Basin Simulator (tRIBS) [Ivanov et al., 
$12004 \mathrm{a}, \mathrm{b}]$. We conduct simulations at a nominal resolution of $\sim 78 \mathrm{~m}$ over a period of seven years.

2 The RSM basin represents a challenging study site for hyperresolution simulations due to its

3 complex hydrologic response resulting from the interaction of heterogeneous terrain and soil

4 properties with a seasonal, semiarid climate dominated by the North American monsoon that

5 dramatically affects ecosystem properties. Previously, tRIBS has been applied in this region to

6 small catchments $\left(<100 \mathrm{~km}^{2}\right)$ during summer periods [Vivoni et al., 2010a; Robles-Morua et al.,

7 2012; Méndez-Barroso et al., 2014; Xiang et al., 2014], demonstrating the potential of these

8 hyperresolution simulations to capture the spatiotemporal variability of the hydrologic processes.

9 Building upon these previous works, we extend the spatial scale of the simulations up to a

10 regional watershed and their duration from the summer months to a multiyear period.

11 We pursue two main objectives that address some of the main challenges of

12 hyperresolution simulations of large, complex hydrologic systems. First, we design strategies to

13 setup, test and apply a hyperresolution DHM in a region with sparse hydrologic data. For this

14 aim, we (i) integrated datasets from different sources including ground stations, remote sensing

15 and reanalysis products, (ii) designed procedures to create model forcings and parameterize the

16 model with high-resolution products and (iii) developed methods to gain confidence in

17 simulating the spatiotemporal hydrologic response. To meet the computational demands, the

18 hyperresolution simulations were conducted on a high performance computing cluster. Second,

19 we interpret the spatiotemporal variability of the large datasets of model forcings and outputs

20 using the EOF analysis. For this aim, we captured the dominant patterns that explain the spatial

21 variability of the main hydrologic variables and compared them with basin properties and

22 meteorological and vegetation forcings. We tracked how the weight of these patterns and their

23 correlation evolved in time during annual and seasonal periods with the aim of exploring the 
1 feedbacks among the variables of the hydrologic system and identifying the physical controls.

2 The strategies presented here to pursue our two main goals are intended to be applicable to a

3 broad range of DHMs applied in diverse settings.

4

5 2. Study Area and Datasets

6 2.1. Basin Characteristics

8 Sonora River [Robles-Morua et al., 2012] located in Sonora, Mexico (Fig. 1a). The climate of

9 the region is arid to semiarid with hot conditions and winter temperatures mostly above $0{ }^{\circ} \mathrm{C}$.

10 The mean annual precipitation ranges from $350 \mathrm{~mm}$ to $750 \mathrm{~mm}$ depending on location [Vivoni et

11 al., 2008; Mascaro et al., 2014]. The precipitation regime in northwest Mexico is complex as it

12 is characterized by: (i) a strong seasonality, with relatively wet summers from July to September

13 when $40 \%$ to $80 \%$ of the annual precipitation occurs during the North American monsoon [e.g.,

14 Gochis et al., 2006; Nesbitt et al., 2008], (ii) a high spatiotemporal variability due to distinct

15 weather systems and to the effect of complex terrain [Johnson et al., 2007; Gebremichael et al.,

16 2007; Rowe et al., 2008; Mascaro et al., 2014] and (iii) high inter-annual and inter-decadal

17 variability associated with teleconnections [Gochis et al., 2006; Forzieri et al., 2013].

18 Topography in the RSM basin is rugged with a mean elevation of $1000 \mathrm{~m}$ and a

19 significant relief of about $2000 \mathrm{~m}$ (Fig. 1b) resulting from channel incision [Coblentz and

20 Riitters, 2004; Vivoni et al., 2007a]. The mean slope obtained from a 29-m digital elevation

21 model (DEM) derived from the Advanced Spaceborne Thermal Emission and Reflection

22 Radiometer (ASTER) is $10^{\circ}$ with minimum and maximum values of $0^{\circ}$ and $65^{\circ}$, respectively.

23 The spatial distribution of vegetation is controlled by topography through its effect on

24 precipitation and air temperature. For example, Fig. 2a presents the land cover map derived by 
1 Yilmaz et al. [2008] at 30-m resolution from an unsupervised classification of Landsat 5

2 Thematic Mapper imagery. The dominant land cover classes are subtropical scrublands, located

3 at intermediate elevations from 600 to $900 \mathrm{~m}$, and sparse woodlands, covering the northern part

4 of the basin and areas close to the channel network. Other land cover types include grassland,

5 riparian mesquite and evergreen woodland, each occupying less than $10 \%$ of the basin area

6 (Table 1). Most ecosystems in the RSM basin have a strong phenological cycle, with leaf

7 greening in mid-July and senescence in late September. Additional details on the land cover

8 classes and their associated ecosystem properties can be found in Vivoni et al. [2007a; 2010a]

9 and Méndez-Barroso and Vivoni [2010].

11 Food and Agriculture Organization (FAO) classification. The dominant soil classes are Lithosol, 12 Regosol and Xerosol which account for $\sim 85 \%$ of the basin area (Table 1). The southern portion 13 of the basin at low elevation is dominated by coarse soils with higher hydraulic conductivity, 14 including YC, RC and LC-LE (see Table 1 for description of the IDs), whereas the northern part 15 of the watershed includes less conductive soils with medium texture, such as RM, XM and LM. 16 Hydrographic features of the watershed, including the channel network and floodplains, are 17 shown in Fig. 2c. The main river runs from north to south between two parallel mountain ranges, 18 with ephemeral tributaries flowing from east and west directions. The floodplain zone was 19 delineated using thermal indices from ASTER that allowed separating different materials based 20 on their spectral absorption [see Méndez-Barroso, 2014]. This process was refined through a 21 comparison to geological maps and aerial photographs. In the RSM, human activities are limited 22 to a few rural towns and agricultural farms, mainly located within the floodplain areas. 


\section{2.2. Coordinated Ground, Model-based and Remotely-Sensed Datasets}

In the RSM, meteorological stations from government agencies collect data at daily resolution at only a few locations. This presents an obstacle for hyperresolution hydrologic modeling for a region experiencing strong seasonality and spatially-variable land surface Table 2 presents the characteristics of each dataset, including its source, acronym, variables, resolution, reference and primary usage in this study. Ground observations belong to three networks, with CEA and CONAGUA managed by government agencies and ASU-UNISON installed to study the hydroclimatology of the RSM basin [Vivoni et al., 2007a]. The ASUmeteorological forcings for the simulations were provided by model-based products from the bias with available ground data at the daily scale. Time-varying vegetation parameters were addition, instantaneous MODIS Land Surface Temperature (LST) estimates and aircraft-based 2012], flown during the North American Monsoon Experiment - Soil Moisture Experiment in conditions. To address this, we integrated a variety of ground, model-based and remotely-sensed datasets available from field research networks and resources from the international community. UNISON network had nine stations with sufficiently-long and reliable data on precipitation (P) and surface (top $5 \mathrm{~cm}$ ) soil moisture (SM) to include in this study (see Fig. 2 and Table 3). One station (147) is also an eddy covariance (EC) tower site with a full set of meteorological data and

flux measurements [e.g., Vivoni et al., 2010b; Méndez-Barroso et al., 2014]. Spatially-distributed North American Land Data Assimilation System (NLDAS) [Mitchell et al., 2004], corrected for derived from the Moderate Resolution Imaging Spectroradiometer (MODIS) sensor onboard the EOS Terra and Aqua satellites using weekly or biweekly composites as in Xiang et al. [2014]. In soil moisture (SM) products from the 2D-STAR sensor [Ryu et al., 2010; Mascaro and Vivoni, 2004 (NAME-SMEX04), were used for model testing purposes over the RSM basin. A result of 
1 coordinating the use of these datasets was the ability to force the model with spatiotemporal

2 meteorological and vegetation products and subsequently test the hyperresolution simulations at

3 individual stations over different time periods and in a spatially-distributed manner for particular

4 instances.

5

6 3. Hyperresolution Hydrologic Model Application

7 3.1. Model Description and Domain

9 water and energy balance in a continuous manner [Ivanov et al., 2004a,b]. The model accounts

10 for the spatial variability of terrain, soil, vegetation and hydrometeorological forcing. Basin

11 terrain is represented through a Triangulated Irregular Network (TIN) that contains elevation,

12 channel and boundary nodes and is able to capture the topographic features with a reduced

13 number of elements as compared to the original DEM [Vivoni et al., 2004; 2005]. This is a

14 desirable characteristic for the feasibility of hyperresolution simulations in regional watersheds.

15 The Voronoi polygons derived from the TIN are used as model elements where the water and

16 energy balance equations are solved. In tRIBS, a range of hydrologic processes are simulated,

17 including canopy interception, infiltration and soil moisture redistribution via a modified Green-

18 Ampt scheme [Cabral et al., 1992; Ivanov 2002], lateral water movement in the unsaturated and

19 saturated zones, evaporation from bare soil and wet canopies, plant transpiration, overland flow

20 in the hillslopes and routing in the channel network. For the RSM basin, a TIN consisting of

21618,745 Voronoi polygons or $14.7 \%$ of the original DEM pixels was selected based on a

22 procedure that assessed computational and resolution tradeoffs [Vivoni et al., 2011]. This

23 corresponds to an equivalent (or average) cell size of $78.21 \mathrm{~m}$ in the basin, thus exceeding the

24 hyperresolution criteria of Wood et al. [2011]. Following Vivoni et al. [2005], a higher resolution 
1 of $30 \mathrm{~m}$ was retained within the floodplain boundaries to capture the dynamics of the variable

2 source area occurring near channels. A spatially-variable soil depth was obtained following the

3 method of Saulnier et al. [1997] to mimic the linear decrease observed with elevation at a

4 number of soil pits within a sub-basin of the RSM [see Méndez-Barroso, 2014]. Further details

5 on the model physical processes and domain are described by Ivanov et al. [2004a] and Vivoni et

6 al. [2007b].

7

8

11 with ground observations, following Robles-Morua et al. [2012]. Depending on data availability

12 during the simulation period, a variable number of rain gauges (mean number of 16 in the basin,

13 Table 2) were used to calculate a daily factor to correct precipitation bias, obtained as the ratio

14 between the basin-averaged precipitation from available rain gauges and from NLDAS pixels.

15 Meteorological data from NLDAS were also corrected using data from meteorological stations of 16 the CEA and ASU-UNISON networks. Based on a daily comparison, a single additive bias was

17 applied to adjust atmospheric pressure, a linear relation was used for incoming solar radiation,

18 but no significant differences were found for relative humidity and air temperature at the co-

19 located sites. However, a correction for air temperature was applied to account for elevation

20 differences between the $12 \mathrm{~km}$ NLDAS cell and each Voronoi polygon using a lapse rate of 6.5

$21{ }^{\circ} \mathrm{C} / \mathrm{km}$. Wind speed was adjusted from a $10 \mathrm{~m}$ height in NLDAS to the $2 \mathrm{~m}$ altitude assumed for

22 model input, assuming a logarithmic wind velocity profile [Dingman, 2002].

23 In tRIBS, vegetation parameters required to simulate the interception and

24 evapotranspiration processes can be dynamically updated through the ingestion of spatially- 
1 variable fields [Vivoni, 2012b], allowing the observed vegetation seasonality to be captured.

2 Time-varying vegetation parameters were computed from remotely-sensed data of leaf area

3 index, normalized difference vegetation index, albedo and the fraction of photosynthetically

4 active radiation from MODIS (Table 2). We used the empirical relationships described in

5 Méndez-Barroso et al. [2014] and Xiang et al. [2014] to convert the MODIS products into model

6 vegetation parameters (e.g., vegetation fraction, VF) and linearly interpolated the composite

7 images to obtain daily parameter fields. As a result, only the plant height was specified from the

8 land cover map (Fig. 2a) as static in time. MODIS products represent vegetation conditions in

9 semiarid regions well [Fensholt et al., 2004; Ryu et al., 2012] and comparisons to field data by

10 Méndez-Barroso and Vivoni [2010], Vivoni [2012b] and Méndez-Barroso et al. [2014] show

11 their utility in the RSM. The use of time-varying vegetation parameters instead of static maps

12 and parameters adopted in most modeling exercises is an important feature to improve

13 hyperresolution simulations in seasonal climates, because the ingestion of observed data

14 quantifying spatiotemporal changes in vegetation conditions is expected to enhance the

15 simulation of physical processes dependent on vegetation dynamics.

16

\subsection{Model Testing at Individual Stations and the RSM Basin}

Model parameterization for the hyperresolution simulations consisted of specifying static soil parameters initially derived from soil texture information and modified through calibration.

The model testing process was aided by having all soil types, except for LM, represented at the nine ASU-UNISON stations with precipitation and soil moisture observations (Table 3). Given the large, complex basin and its limited number of ground stations, we designed a calibration and validation approach to take advantage of the available data for the different soil types. The model was setup at each individual station, following Vivoni et al. [2010a] and Méndez-Barroso et al. 
1 [2014], using a single Voronoi polygon (area of $100 \mathrm{~m}^{2}$ ). Soil parameters were calibrated and

2 validated at each station for the specific soil class and assumed valid over basin areas with the

3 same soil type. To support this assumption, the percentages of sand and silt obtained from soil

4 samples collected at the stations were compared with those provided by the ISRIC-WISE

5 international soil dataset (http://www.isric.org/data/isric-wise-international-soil-profile-dataset)

6 that formed the basis for the soil classifications (Fig. 2b). As shown in Table 3, soil texture

7 compositions from the sources are similar at all locations, supporting the approach.

9 selected depending on data availability and quality (Table 3). Each simulation includes an entire

10 monsoon season preceded by a dry month that, for these configurations based on a single

11 Voronoi polygon, we found to be sufficient to isolate the effect of the initial conditions. The

12 model was initialized assuming a condition of $25 \%$ saturation of the total soil depth (for

13 example, in a cell with a soil depth of $1 \mathrm{~m}$, we assumed the water table located at a depth of 0.75

$14 \mathrm{~m}$ ) and no lateral or vertical flow. Precipitation data observed at the station were used as model

15 inputs, while other meteorological forcings and vegetation parameters were provided by co-

16 located NLDAS and MODIS pixels. To minimize the number of calibrated parameters, the

17 pedotransfer function of Saxton et al. [1986] was used to assign the porosity (n), saturated

18 hydraulic conductivity $\left(K_{s}\right)$ and saturated soil moisture content $\left(\theta_{s}\right)$ from the ISRIC-WISE

19 texture of each station. The Shuffled Complex Evolution technique [Duan et al., 1992] was then

20 applied to calibrate the residual soil moisture content $\left(\theta_{r}\right)$, pore size distribution index $(m)$,

21 conductivity decay parameter $(f)$ and stress thresholds for evaporation $\left(\theta_{e}^{*}\right)$ and transpiration $\left(\theta_{t}^{*}\right)$

22 at each station. Parameter values were sampled within physically meaningful ranges for each soil

23 class. For the LM soil type not represented at a station, the pedotransfer function for the texture 
1 provided by ISRIC-WISE was used to derive $n, K_{s}$ and $\theta_{s}$, while the other calibration parameters

2 were assumed equal to the LC-HE class. The calibrated soil parameters are reported in Table 4.

3 For all classes, the air entry bubbling pressure $\left(\Psi_{b}[\mathrm{~mm}]\right)$ was assumed equal to 0 to limit the

4 influence of the capillary fringe on surface SM in shallow soils and the conductivity anisotropy

5 ratio $\left(A_{s}[-]\right)$ was set equal to 1, following Vivoni et al. [2010a]. As in Xiang et al. [2014], we

6 utilized dry and wet values for the soil heat conductivity $\left(k_{s}\right.$ of 1.2 and $\left.0.2 \mathrm{~J} / \mathrm{msK}\right)$ and soil heat

7 capacity $\left(C_{s}\right.$ of $6 \times 10^{5}$ and $\left.1.47 \times 10^{6} \mathrm{~J} / \mathrm{m}^{3} \mathrm{~K}\right)$ based on a soil moisture threshold of $0.021 \mathrm{~m}^{3} / \mathrm{m}^{3}$ for 8 all classes.

9 For the RSM basin, the hyperresolution model was applied continuously from 1 January

102004 to 31 December 2010, with soil parameters from the station simulations, vegetation

11 parameters from MODIS and bias-corrected meteorological forcings from NLDAS. To set the

12 initial conditions in the basin, a preliminary model run lasting 7 years was carried out using the

13 same meteorological forcings and starting from a condition of $25 \%$ saturation of the total soil

14 depth, as done for the simulations at individual stations. After 5 years, the fluctuations of the soil

15 water storage reached stationary conditions (not shown). The model states at the end of this

16 preliminary run, including the soil moisture profile in the unsaturated zone, were then used as

17 initial conditions. Hyperresolution model outputs included hourly time series at station locations

18 and daily spatial maps of instantaneous and cumulative values of hydrologic state variables and

19 fluxes. Model performances of station and basin simulations were tested by comparison of time

20 series of surface SM and LST at the nine stations and of latent heat flux at the EC tower. In

21 addition, simulated maps of surface SM and LST were compared to remotely- sensed surface SM

22 from 2D-STAR and LST from MODIS. For both variables, comparisons were made for the five 
1 days when 2D-STAR was available (7, 8, 24-26 August 2004) during NAME-SMEX04 at the

2 times coincident with the aircraft or satellite overpass, respectively.

3

4 3.4. Numerical Experiments on a High Performance Computing Cluster

11 parallel operations) and waiting (queue) time to access the shared cluster resources. In addition,

12 since the total job time in this cluster was limited to $96 \mathrm{~h}$ and the entire simulation required $\sim 600$

$13 \mathrm{~h}$ on 64 processors, the run was divided into pieces using a hot restart mechanism that allows

14 saving and reading the full model states. Spatial maps were generated by merging files outputted

15 by each processor which solves the model processes in the sub-basin assigned to it by the

16 partitioning scheme. The model produced a large output dataset including a total of 2557 daily

17 spatial maps (accounting for all 618,745 nodes) for each variable and time series at hourly

18 resolution at $\sim 52$ distributed locations near the nine stations. To handle this size, we limited the

19 number of variables outputted by the model from the standard set of 109 instantaneous and

20 cumulative states and fluxes to a reduced set of 35 variables and converted the standard text files

21 into binary format, obtaining a total output dataset with a size of $\sim 165$ Gigabytes. 


\section{3.5. Model Output Analysis using Empirical Orthogonal Functions}

Model outputs from the long-term hyperresolution simulations were analyzed through

3 EOF analysis [Hannachi et al., 2007]. For a space-time field, EOF analysis identifies a set of

4 orthogonal spatial patterns (EOFs), along with a set of time series of coefficients (Principal

5 Components, PCs) that control the contribution of each EOF in time. The analysis can be applied

6 on (i) the spatial anomalies computed for a given time by subtracting the variable of interest from

7 the spatial mean, with the aim of identifying a set of few patterns (or EOFs) that explain a large

8 portion of the spatial variability or (ii) the temporal anomalies, computed by subtracting the

9 variable of interest from the temporal mean, with the goal of finding locations where the variable

10 has limited or large variations in time. We applied the technique based on the spatial anomalies

11 on the main model forcings (precipitation, $\mathrm{P}$, vegetation fraction, $\mathrm{VF}$ ) and three output variables

12 (soil moisture, SM, evapotranspiration, ET, runoff, Q) generated locally in each model element.

13 We applied EOF analysis to both spatial and temporal anomalies for evapotranspiration and 14 runoff ratios (ET/P and Q/P, respectively). Details of the EOF analysis are provided in Appendix

15 A. For precipitation and the model outputs, we applied the analysis on unstructured meshes, 16 while for vegetation fraction the approach used the remotely-sensed product at $250 \mathrm{~m}$ resolution.

17 To compute the correlation coefficients among EOFs from different spatial domains, variables in 18 the irregular mesh were resampled to the regular grid, weighting values from Voronoi polygons 19 by the area included in the square pixel. We conducted the EOF analysis for variables aggregated 20 at (i) the monthly scale to study the annual cycle of the watershed response and (ii) the daily 21 scale to focus on the seasonal evolution during the North American monsoon. In all applications, 22 the first two EOF/PC pairs were found to be statistically significant at $90 \%$. 


\section{4. Results}

2 4.1. Model Performance at Individual Stations and the RSM Basin

3 Comparisons between observed and simulated surface SM at individual stations are

4 shown in Fig. 3 for calibration periods, with the quantitative model performances assessed for

5 calibration and validation periods using three metrics - Mean Absolute Error (MAE), Bias (B)

6 and Correlation Coefficient (CC) - in Table 5. When available, the 2D-STAR SM retrievals

7 obtained at co-located pixels with the stations are also shown. Note the model ability to capture

8 the alternating periods of wet and dry conditions across all stations representing a wide range of

9 soil, vegetation and precipitation conditions. Peak SM values and recession characteristics are

10 simulated well in most cases. Note that the sharp decreases simulated at some stations (e.g., 133,

$11144,143)$ are due to the soil moisture redistribution mechanism that resets the soil moisture

12 profile based on the groundwater table position at the current time after an interstorm period of

$13 \sim 4$ days [see Ivanov, 2002 for details]. When inspected across all stations, a low MAE

$14\left(0.019 \pm 0.007 \mathrm{~m}^{3} / \mathrm{m}^{3}\right)$, high CC $(0.917 \pm 0.031)$ and B near zero $\left(-0.0003 \pm 0.013 \mathrm{~m}^{3} / \mathrm{m}^{3}\right)$ indicate

15 an excellent performance in the calibration period, with a slight degradation in the validation

16 period (Table 5). In addition, the model correspondence to the 2D-STAR product exhibits small

17 differences that are mainly attributed to the retrieval algorithm [Ryu et al., 2010]. As an

18 independent test, the insets in Fig. 3 show scatterplots of observed and simulated LST, with

19 values mostly along the $1: 1$ line. The relatively low $\operatorname{MAE}\left(5.2 \pm 0.68^{\circ} \mathrm{C}\right.$ and $6.3 \pm 2.41{ }^{\circ} \mathrm{C}$ for

20 calibration and validation periods, corresponding to about $16 \%$ and $19 \%$ in relative terms) shows

21 the model skill to simulate LST across all stations. Latent heat flux was also evaluated against

22 data at the EC tower for summer 2004, leading to results similar (MAE $=39.1 \mathrm{~W} / \mathrm{m}^{2}, \mathrm{~B}=-9.5$

$23 \mathrm{~W} / \mathrm{m}^{2}$ and $\left.\mathrm{CC}=0.62\right)$ to those reported by Vivoni et al. [2010a]. Overall, these tests indicate that 
1 the summer season simulations at the individual stations reproduce well the soil moisture

2 response to precipitation, land surface temperature dynamics and evapotranspiration flux.

The basin simulations were evaluated in two ways. First, we computed the three metrics

4 for SM for the co-located Voronoi polygons at the nine stations (Table 5). A lower skill is seen

5 as compared to individual runs. Possible reasons include the use of precipitation forcings from

6 NLDAS and the effects of lateral transport represented only in the basin model. While the model

7 overestimates SM $\left(B=0.034 \pm 0.028\right.$ and $0.028 \pm 0.042 \mathrm{~m}^{3} / \mathrm{m}^{3}$ in calibration and validation

8 periods), the other metrics indicate fairly good performance, as revealed by the low MAE

$9 \quad\left(0.051 \pm 0.029\right.$ and $\left.0.060 \pm 0.028 \mathrm{~m}^{3} / \mathrm{m}^{3}\right)$ and high $\mathrm{CC}(0.748 \pm 0.097$ and $0.754 \pm 0.127)$. Second, the

10 spatial patterns of simulated SM and LST were compared to remote sensing products from 2D-

11 STAR and MODIS as independent validations. Fig. 4 shows examples for wet (8 August 2004)

12 and dry (25 August 2004) days. On the wet day, the simulation and 2D-STAR agree in terms of

13 capturing wetter conditions in the southern portion of the domain, but the model has higher SM

14 in the northeast region consistent with the station data. On the dry day, the model and 2D-STAR

15 both exhibit lower SM throughout the basin with wetter areas occurring in mountain fronts.

16 Furthermore, the simulated and remotely-sensed LST patterns are similar in both days with a

17 good representation in the model of the elevation and latitudinal controls on LST. Table 6

18 provides the model performance metrics, showing that $\mathrm{CC}$ for $\mathrm{SM}$ is low $(0.152 \pm 0.076)$,

19 indicating weak pixel-to-pixel correspondence, but the low B $\left(0.023 \pm 0.032 \mathrm{~m}^{3} / \mathrm{m}^{3}\right)$ and low

$20 \operatorname{MAE}\left(0.043 \pm 0.021 \mathrm{~m}^{3} / \mathrm{m}^{3}\right)$ are similar to metrics obtained between SM data at stations and 2D-

21 STAR. Model performance is superior for LST, with a relatively high CC, low B and low MAE.

22 Variations in performance are attributed to the coarse precipitation forcing (12-km) from

23 NLDAS that affect simulated SM as compared to the elevation-corrected air temperature forcing 
1 that serve as the primary control on LST. Overall, the model evaluations against different

2 independent observations of spatial and temporal patterns build confidence in the model ability

3 to capture the watershed behavior.

4

\subsection{Temporal and Spatial Variability of Basin Hydrologic Response}

We assess the hydrologic response by first inspecting the temporal evolution of basinaveraged conditions during the long-term simulation. Fig. 5 presents the daily $\mathrm{P}$ and vegetation forcing (depicted as normalized difference vegetation index, NDVI) and a set of model outputs the daily surface (top $5 \mathrm{~cm}$ ) and root zone (top $1 \mathrm{~m}$ ) SM, LST, ET and Q at the outlet. All variables exhibit seasonality due to the North American monsoon, with summer (July-

September) precipitation accounting for $\sim 73 \%$ of the annual totals of $727 \pm 120 \mathrm{~mm}$. Precipitation

seasonality affects the response of vegetation as revealed by a peak NDVI in August that varies each year [e.g., Forzieri et al., 2011]. Surface SM is high during each summer with frequent

fluctuations associated with convective storms, while winter season (December-February) conditions are dry, but interrupted by isolated frontal storms. As expected, root zone SM has lower fluctuations in time than surface SM and exhibits sharp increases during the summer followed by long recessions. LST, on the other hand, is composed of a strong annual cycle and high-frequency fluctuations related to weather variability. Note that basin-averaged LST peaks at the end of June, before the onset of the summer monsoon, after which it decreases substantially 
1 summer season ET/P of $60 \pm 13 \%$ and an annual ET/P of $78 \pm 9 \%$ during the simulation years

2 which exhibit a wide range of climate conditions. Since in this semiarid region the channel

3 transmission losses (i.e. the infiltration of water along the main stream) are significant [e.g.,

4 Goodrich et al., 1997] and tRIBS is not currently able to represent this process, Q routed at the

5 outlet is expected to be overestimated. Despite that, the model indicates that significant runoff

6 events mostly occur during summer and after some sporadic winter storms.

7 Next, the spatial distribution of time-averaged hydrologic variables is inspected during

8 the summer and winter seasons. Fig. 6 presents the seasonal precipitation forcing, surface SM

9 and ET, illustrating the marked differences between wet (summer) and dry (winter) conditions.

10 While the precipitation forcing is limited to the NLDAS resolution, it displays different spatial

11 variations in each season related to latitudinal and orographic effects [e.g., Gebremichael et al.,

12 2007; Mascaro et al., 2014]. The spatial patterns of surface SM and ET are represented at the

13 hyperresolution ( $\sim 78 \mathrm{~m}$ equivalent cell size with a standard deviation, maximum and minimum

14 of 25, 288 and $1 \mathrm{~m}$, respectively) of the model. At this resolution, surface SM and ET exhibit

15 patterns that reflect the combined effects of precipitation forcing, topographic properties, soil

16 conditions and vegetation seasonality. Disentangling these controls based solely on average

17 seasonal distributions of SM and ET is not straightforward. Nevertheless, signatures of the soil 18 types (Fig. 2b) are evident in the SM distribution for the drier winter season. In the summer, the 19 terrain-mediated lateral redistribution of soil water and the variation of plant water extraction in 20 the seasonal ecosystems (Fig. 2a) confound the spatial patterns of surface SM and ET [e.g., 21 Vivoni et al., 2010a]. In addition to the visual inspection of basin-averaged time series and time22 averaged spatial maps, long-term simulations in regions with complex characteristics require 23 analysis techniques that are able to quantitatively describe the spatiotemporal linkages between 
2

model forcings and the basin hydrologic response, as explored in the following.

\subsection{Interpretation of Spatiotemporal Hydrologic Variability using EOF Analyses}

We implemented several types of EOF analyses to explore the spatiotemporal evolution of the hydrologic model forcings and response variables and their relationships to static basin properties. To capture this linkage, a correlation analysis was carried out between the first two EOFs of all variables and the basin properties, specifically terrain elevation $(z)$, local slope $(\beta)$, wetness index ( $\lambda$, Beven and Kirkby [1979]) and saturated hydraulic conductivity $\left(K_{s}\right)$. To first understand the main model forcings, Fig. 7 shows the spatial patterns of the first two EOFs of precipitation (P) and vegetation fraction (VF) from monthly analyses (84 EOF/PC pairs, 12 months in 7 years). Monthly analyses depict the dominant spatial patterns of the annual cycle of hydrologic conditions over multiple years of simulation. Note the latitudinal and orographic variations in EOF1-P (51\% of explained variability) and EOF2-P (21\%). While the pattern of EOF2-P is clearly seen in winter and summer precipitation distributions (Fig. 6), that of EOF1-P was only revealed through the EOF analysis. As shown in Table 7, elevation has a stronger control on EOF1-P $(\mathrm{CC}=0.67)$ than EOF2-P $(\mathrm{CC}=0.28)$, since the latitudinal variation is concomitant with an elevation increase. As expected, the EOFs of VF exhibit patterns that reflect the land cover map (Fig. 2a) and terrain properties, with high CCs of EOF1-VF (67\%) with $\beta$

$(\mathrm{CC}=0.56)$ and EOF2-VF $(13 \%)$ with $z(\mathrm{CC}=-0.50)$. As a result of the elevation control on both $\mathrm{P}$ and VF, the CC between EOF2-VF and EOF1-P is relatively high (-0.37), although the other relationships are weak $(-0.19<\mathrm{CC}<0.16)$. Associated with the EOF patterns are the monthly PCs, shown in Fig. 8 in terms of monthly averages over the simulation period for P and VF (Figs. 8a,b). Precipitation seasonality is reflected in non-zero PC values during the North American monsoon (JAS). In July, both EOFs influence P since PC1-P and PC2-P are non-zero, 
1 while PC2-P clearly dominates in August and September, thus explaining how EOF2-P and the

2 summer precipitation pattern are similar. Vegetation seasonality is captured well by the behavior

3 of PC1-VF and PC2-VF, with an increase during the summer monsoon and a peak in August. An

4 interesting observation is the change in sign of PC2-VF for the months of October to May. Since

5 EOF2-VF is linked with $z$, this indicates that elevation controls on VF are reversed during the

6 summer. We interpret this as a measure of how ecosystem greenness varies substantially with

7 elevation in the winter, while the summer season brings about a homogeneously green landscape.

8 The hydrologic model response is assessed with monthly EOF analyses of surface SM,

9 ET and Q generated at each Voronoi polygon. The hyperresolution outputs are a result of the 10 complex interactions of the model forcings with variable resolution (e.g., P and VF) and the 11 terrain (e.g., $z$ and $\beta$ ), soil (e.g., $K_{s}$ ) and wetness (e.g., $\lambda$ ) properties of the basin. Fig. 9 shows the 12 first two EOFs of surface SM, ET and Q, while Table 7 quantifies the CCs between the EOFs 13 and these individual factors. As in Jawson and Niemann [2007], the EOFs do not show high CCs 14 (usually less than \pm 0.5 ), though meaningful interpretations can be derived. For example, EOF1$15 \mathrm{SM}(61 \%)$ has a relatively strong signature of the soil classes $\left(\mathrm{CC}=-0.30\right.$ with $\left.K_{s}\right)$, while the 16 EOF1-ET (57\%) is mainly controlled by vegetation parameters ( $\mathrm{CC}=0.37$ with $\mathrm{VF})$, with minor 17 contributions of $\lambda$ to each ( $\mathrm{CC}=0.22$ and 0.32 , respectively) since this is a proxy for soil water 18 accumulation due to lateral transport. While relatively weak controls appear for EOF2-SM $19(14 \%)$, the pattern of EOF2-ET $(15 \%)$ is associated strongly with EOF1-VF $(\mathrm{CC}=-0.59)$ and $z$ $20(\mathrm{CC}=-0.40)$, which is linked to air temperature. Interestingly, EOF1-Q $(68 \%)$ and EOF2-Q $21(10 \%)$ show patterns that resemble EOF1-SM and EOF2-ET, respectively, an indication of the 22 varied controls on runoff generation. Note the moderately strong relations to $\lambda, z$ and EOF1-VF. 23 The temporal variations are depicted through the monthly average PCs in Figs. 8c-e and can be 
1 compared to PCs for P and VF (Figs. 8a,b). Clearly, a seasonal signature related to the North

2 American monsoon is present in all PCs as well as a local maximum or minimum in the winter

3 for both PCs of SM and Q when hydrologic activity is present, but vegetation is dormant. For

4 evapotranspiration, PC1-ET has stable values with small decreases in summer, while PC2-ET

5 has a stronger summer increase. This is indicative of a stable contribution of VF during the year

6 (PC1-ET) to ET and an important modification via an elevation control on air temperature (PC2-

7 ET) in the summer. A notable switch in PC2-Q from July to September suggests that VF changes

8 during the North American monsoon, through its influence on ET, impact runoff patterns.

9 To explore the temporal evolution during the North American monsoon in more detail, 10 we carried out EOF analyses at the daily scale (644 EOF/PC pairs, 92 days in 7 summers). For $\mathrm{P}$ 11 and VF, the first two EOFs explain $\sim 75 \%$ of the variability (Table 7), similar to the monthly

12 analysis. In contrast, the first two EOFs explain a significantly smaller variance for model 13 outputs (19\%, 30\% and 14\% less for SM, ET and Q), implying that hydrologic responses are 14 characterized by higher spatial randomness at smaller time scales. Nevertheless, CCs between 15 model outputs and individual factors can be higher when the analysis is conducted at daily scale. 16 This is true for both forcings (e.g. CCs of EOFs of VF with EOF2-SM and EOF2-Q) and basin 17 properties (e.g., CCs of EOF1-SM, EOF1-ET and EOF1-Q with $z, \beta, K_{s}$ and $\lambda$ ). As a result, the 18 summer season evolution of the hydrologic response is a complex function of forcings and local 19 conditions that are captured better through daily analyses. Fig. 10 presents the daily averages of 20 the first two PCs. The random distribution of the PCs of P and the slowly varying PCs of VF 21 represent well the dynamics of convective precipitation and vegetation seasonality. In response 22 to these model forcings, the PCs of SM exhibit slowly varying characteristics, while the PCs of 23 ET and Q are influenced to a greater degree by precipitation. It is interesting to note that EOF1- 
2 indicating that spatial variability of SM is governed primarily by soil properties and terrain

3 attributes (see CCs in Table 7) during the wet season. Since PC1-ET is greater than PC2-ET in

4 its absolute value throughout the summer, EOF1-ET has a stronger role on ET patterns that are

5 influenced by VF and terrain features. While the daily scale is useful for interpretations, the

6 noise introduced by precipitation can obscure the seasonal evolution that was observed from the

7 monthly analyses, as seen for the PCs of Q exhibiting random fluctuations aligned with the PCs

8 of $\mathrm{P}$.

\subsection{Spatiotemporal Variability of Evapotranspiration and Runoff Ratios}

To further study the seasonal evolution of the hydrologic response, we use the monthly variation of the evapotranspiration ratio $(\mathrm{ET} / \mathrm{P})$ and the runoff $(\mathrm{Q} / \mathrm{P})$ ratios as measures of water balance partitioning [e.g., Koster and Mahanama, 2012; Liu et al., 2013a]. Spatial distributions of ET/P and Q/P are shown in Fig. 11 for the three summer months (JAS), each averaged over the simulation period. Overall, both ratios increase during the summer. For ET/P, this is caused by a larger decrease in monthly average $\mathrm{P}(206,179$ and $107 \mathrm{~mm}$ in JAS) as compared to ET (113, 108 and $75 \mathrm{~mm}$ in JAS) due to greater soil water and vegetation greenness [e.g., MéndezBarroso et al., 2014]. Monthly ET/P can be larger than 1 when ET accounts for precipitation from prior months through accumulated soil moisture. The growth of $\mathrm{Q} / \mathrm{P}$ from July to September is related to an increase in the monthly average Q $(11,21$ and $28 \mathrm{~mm}$ in JAS) as well as the reduction in $\mathrm{P}$ [e.g., Robles-Morua et al., 2012]. For each month, ET/P and Q/P patterns depend on interactions of precipitation with terrain, soil and vegetation properties that vary in time as the basin becomes wetter during the North American monsoon, as investigated next using EOF analyses. 
2 with respect to both spatial and temporal anomalies using the corresponding EOF/PC pairs, as

3 shown in Fig. 12. Table 8 reports the percentage of total variability explained by the first two

4 EOFs of each variable, as well as the CCs between the EOFs and the basin properties or model

5 forcings. For the spatial anomalies, EOF1-ET/P (55\%) and EOF1-Q/P (70\%) resemble the

6 monthly spatial patterns shown in Fig. 11, with the major controls exerted by slope $(\beta)$ and

7 wetness index $(\lambda)$ and by EOF1-VF in the latter case. While EOF2-ET/P (19\%) recovers EOF1-P

$8 \quad(\mathrm{CC}=-0.75)$ capturing the latitudinal changes of precipitation, $\mathrm{EOF} 2-\mathrm{Q} / \mathrm{P}(10 \%)$ has elevation

$9(\mathrm{CC}=-0.35)$ and EOF2-VF $(\mathrm{CC}=-0.34)$ controls, suggesting an interaction between runoff and 10 vegetation dynamics. For the temporal anomalies, values close to zero in Fig. 12 (black) indicate 11 regions with higher temporal stability, while non-zero values exhibit higher variations in time. 12 As shown in Table 8, the temporal anomalies (italics) are more strongly explained by the first 13 EOF of ET/P and Q/P, with higher CCs with $z$, EOF1-P and EOF1-VF, indicating that these 14 factors exert a greater effect on temporal variations. All EOFs have values close to zero in the 15 southernmost part of the basin, where ET/P tends to be relatively high and constant, while $\mathrm{Q} / \mathrm{P}$ is 16 near zero all the time. Other time-stable areas appear in EOF2-ET/P in response to the EOFs of $\mathrm{P}$ 17 and in the EOFs of Q/P due to a combination of $K_{s}$ and the EOFs of P. The monthly average PCs 18 of the spatial EOFs of ET/P and Q/P are shown in Fig. 13. For both ratios, PC1 increases from 19 July to September and is larger than PC2, which is relatively constant. This indicates that the 20 influence of $\lambda$ (associated to EOF 1-ET/P at $\mathrm{CC}=0.36$ and EOF $1-\mathrm{Q} / \mathrm{P}$ at $\mathrm{CC}=0.29$ ) grows as the 21 basin becomes wetter. A secondary factor for the increase in $\mathrm{PC} 1$ of $\mathrm{EOF} 1-\mathrm{Q} / \mathrm{P}$ is the relation 22 with EOF $1-\mathrm{VF}(\mathrm{CC}=0.26)$ accounting for vegetation. In contrast, the influence of precipitation 23 and $z$ (both associated to EOF2-ET/P and EOF2-Q/P) lead to a constant effect (stable PC2s) on 
1 the spatial patterns of ET/P and Q/P during the summer season.

2

3 5. Discussion

\section{5.1. Identification of Physical Controls on Spatiotemporal Dynamics using EOFs}

\section{EOF analyses of hyperresolution simulations can provide novel insight into the controls} on hydrologic variability in complex, regional watersheds. This technique presents, in fact, distinct advantages as compared to methods typically adopted to interpret outputs of hydrologic models, as it (i) integrates the spatial and temporal dimensions through the combined use of EOFs (spatial maps) and coefficient of PCs (time series); (ii) preserves the spatial correlation assuring that possible connectivity or emergent patterns are represented and quantified; (iii) does not require, in principle, spatial or temporal aggregation of model outputs, forcings and basin properties used to parameterize the model; and (iv) synthesizes a large amount of information. In this study, we found that a large portion of the variability (from $58 \%$ to $80 \%$ ) can be explained by the first two EOFs for model forcings and outputs at different time scales. When applied at a monthly scale, the annual cycle induced by the North American monsoon is clearly revealed, while reducing the random effects of individual storms that is apparent at daily scales. We identified that spatial variations for all hydrologic variables are only significant when the system is wet during the summer season or brief periods in the winter. During wet conditions, terrain controls on soil water redistribution have an important impact on the spatial patterns of all model outputs through the first EOF, confirming Vivoni et al. [2007a; 2010a] who found terrainmediated redistribution in a small basin in the RSM. Other factors were found to influence model outputs via the first or second EOF, including soil texture for soil moisture patterns and vegetation fraction and elevation for evapotranspiration and runoff distributions. EOF analyses at the daily scale further revealed the seasonal evolution during the North American monsoon, with 
1 stronger relations between model outputs and the basin properties and model forcings. The

2 influence of vegetation seasonality on runoff patterns occurs through the evapotranspiration of

3 soil water whose content affects runoff generation [e.g., Newmann et al., 2006; Robles-Morua et

$4 a l ., 2012]$. As the wet season progresses, vegetation also controls the evolution of the runoff

5 ratio. Identifying this relatively indirect link highlights the ability of EOF analyses to disentangle

6 complex relations within large, hydrologic model datasets.

7

8

9

\subsection{Features of the Hydrologic Response in the North American Monsoon Region}

Aided by the EOF analyses, the water balance partitioning allows elucidating the main features of the watershed response for areas influenced by the North American monsoon, as presented by Shen et al. [2013] for a humid basin. In northwest Mexico, precipitation has a pronounced interannual variability [Gochis et al., 2006], as shown by annual P ranging from 545 to $879 \mathrm{~mm}$ during the study period. Since most precipitation ( $70 \%$ of $727 \pm 120 \mathrm{~mm})$ occurs during the North American monsoon when radiation is maximum [Vivoni et al., 2010a], summer ET accounts for $\sim 54 \%$ of the annual totals of $560 \pm 82 \mathrm{~mm}$ and summer ET/P is $\sim 60 \pm 13 \%$. ET/P progressively grows during the summer season from $\sim 55 \%$ to $\sim 70 \%$ (July to September) as the basin becomes wetter and vegetation greenness increases. Correspondingly, ET/P reflects more the terrain attributes related to soil water redistribution, indicating a higher ET near the channel network as the season evolves. Interestingly, summer ET does not vary significantly across years $(296 \pm 38 \mathrm{~mm})$ as compared to summer $\mathrm{P}(491 \pm 111 \mathrm{~mm})$. This suggests that interannual variations in vegetation greenness adapt to water availability to lead to a stable evaporative demand, with any excess water during a particular summer leading to a higher $\mathrm{Q} / \mathrm{P}$. The progressive wetting in regional watersheds affected by the North American monsoon also leads to a significant growth in $\mathrm{Q} / \mathrm{P}$ [Robles-Morua et al., 2012] from $\sim 5 \%$ to $\sim 26 \%$ (July to September). The growth in Q/P 
1 is associated with stronger relations to spatial patterns in soil water redistribution and vegetation

2 greening. Furthermore, temporal EOF analyses identified areas within the watershed with stable

3 ET/P and $\mathrm{Q} / \mathrm{P}$ contributions in time that can be associated with water vapor source areas [e.g.,

4 Bosilovich et al., 2003; Dominguez et al., 2008] or regions with consistent runoff potential.

5

6 5.3. Towards Hyperresolution Hydrologic Modeling in Regional Watersheds

Through a combination of modeling techniques and EOF analyses, we addressed several challenges in hyperresolution simulations. Computational efficiency was achieved in the regional watershed by using an irregular domain [Vivoni et al., 2004, 2005] and approximate solutions in the infiltration and routing schemes [Cabral et al., 1992; Ivanov et al., 2004a]. A parallel version of the model tailored for a high performance computing cluster allowed long-term simulations to be conducted [e.g., Vivoni et al., 2011; Mascaro et al., 2013; Piras et al., 2014]. Nevertheless, computational constraints limited our ability to carry out automated calibration of the full model run, as in Moreno et al. [2013]. To circumvent this, we designed a strategy to transfer parameters from runs at individual stations to entire soil classes in the basin simulation. The calibration was strongly constrained by using high-resolution terrain, soil and time-variable meteorological and vegetation observations which allowed identifying the values of a few soil parameters within physically plausible ranges. Thus, the high process fidelity retained in the model resulted in a robust performance with respect to independent observations of hydrologic variables at specific sites and remotely-sensed spatial patterns over particular instances. The spatiotemporal tests spanned a wide range of hydrologic processes related to surface soil moisture, latent heat flux and land surface temperature. After building confidence in the hyperresolution simulation, EOF analyses of model inputs and outputs were used to explore the spatiotemporal dynamics of the high-dimensional hydrologic system. To apply these statistical processing methods, we designed 
1 techniques to efficiently store, query and manipulate the large model outputs. In this study, we

2 used a standard technique that identifies orthogonal EOFs that may create difficulties for systems

3 where physical modes are not orthogonal [Dommenget and Latif, 2002]. A fruitful next step in

4 the application of these tools for hyperresolution model interpretations should be the use of

5 rotated EOF methods designed to address this limitation [Hannachi et al., 2007].

6

7 6. Concluding Remarks

9 simulations in regional watersheds with limited ground data. To do so, strategies were developed 10 to setup, test and apply the model by integrating datasets from different sources. Simulations 11 were performed on a high performance computing cluster to meet the computational demands. 12 Given the high-dimensionality of the hyperresolution outputs, EOF analyses at multiple time 13 scales proved effective in visualizing the major patterns and extracting relationships to basin 14 characteristics and model forcings. Despite the complexities involved in long-term simulations 15 that capture features at high-resolution, the spatiotemporal model outputs can be explained well 16 by two dominant EOFs, whose weight varies with the time of the year and basin wetness. This 17 suggests that hydrologic interpretations from hyperresolution simulations are aided by techniques 18 that aggregate information in meaningful ways. Thus, the push toward hyperresolution modeling 19 at regional or global scales must be accompanied by the use of techniques to extract the emergent 20 patterns arising from the time-variable interactions of terrain, soil, vegetation and meteorological 21 conditions. The coupled use of mathematical modeling and statistical processing will be essential 22 in meeting the challenges of hyperresolution hydrologic simulations across a range of settings. 


\section{Acknowledgements}

2 We thank three anonymous reviewers for their comments that helped to improve the

3 quality of the manuscript. We would also like to thank funding from the NOAA Climate

4 Program Office (Grants GC07-19 and NA10OAR4310165), NSF IRES Program (Grants OISE

50809946 and OISE 0553852) and the U.S. Army Research Office (Grant 56059-EV-PCS). The

6 bi-national NAME-SMEX04 project gave an important impetus for field observations and

7 modeling activities in the study region. We acknowledge the computing facilities from the ASU

8 Advanced Computing Center. We also thank Christopher J. Watts, Julio C. Rodríguez, Juan A.

9 Saíz-Hernandez, Enrico A. Yépez, Jaime Garatuza-Payan, Agustin Robles-Morua and Tiantian

10 Xiang who contributed to the data collection and processing efforts. Field data sets are available

11 through data catalogs at http://catalog.eol.ucar.edu/name/ and

12 http://vivoni.asu.edu/sonora/www/pages/hydromet.html. 


\section{Appendix A}

3 [2007]. Let $y_{i}(t)$ be a variable simulated at a location $i$ and time $t$. Suppose that $m$ is the number

4 of locations in the spatial field and $n$ is the number of times when the variable is available. In our

5 application, the locations are the centroids of the Voronoi polygons in the unstructured mesh

6 when dealing with model outputs and the centers of the regular grids when considering

7 vegetation fraction. The EOF analysis can be applied to the spatial anomalies, $x_{i}(t)$, defined as:

$$
x_{i}(t)=y_{i}(t)-\frac{1}{m} \sum_{j=1}^{m} y_{j}(t) .
$$

9 The anomalies can be organized in a matrix $\mathbf{X}(m \times n)$ containing a spatial field in each of the $n$ 10 columns (i.e. times). The analysis requires computing the covariance matrix $\mathbf{R}_{\mathbf{s}}(n \times n)$ of $\mathbf{X}$ as:

$$
\mathbf{R}_{\mathbf{s}}=\frac{1}{m} \mathbf{X}^{\mathrm{T}} \mathbf{X}
$$

12 where the superscript $\mathrm{T}$ indicates the transpose. Next, the eigenvectors of $\mathbf{R}_{\mathbf{s}}$ are calculated as:

$$
\mathbf{R}_{\mathrm{s}} \mathbf{E}_{\mathrm{s}}=\mathbf{L}_{\mathrm{s}} \mathbf{E}_{\mathrm{s}}
$$

14 where $\mathbf{E}_{\mathbf{s}}(n \times n)$ is the matrix of the eigenvectors (contained in each column) and $\mathbf{L}_{\mathbf{s}}(n \times n)$ is the 15 diagonal matrix of the corresponding eigenvalues. The eigenvectors are called Principal 16 Components (PCs). The spatial patterns associated to each eigenvector are the EOFs and can be 17 found by projecting the original anomaly dataset into the new space defined by the eigenvectors:

$19 \mathbf{F}_{\mathbf{s}}(m \times n)$ is the matrix containing the EOFs. Thus, the EOF analysis decomposes a dataset of 20 spatial fields available $n$ times at $m$ locations into a set of $n$ orthogonal spatial patterns of size $m$. 21 Each eigenvector (PC) has size $n$ and is a time series of coefficients that control the contribution 22 of each EOF. The original anomaly matrix $\mathbf{X}$ is reconstructed from EOFs and PCs as: 


$$
\mathbf{X}=\mathbf{F}_{\mathbf{s}} \mathbf{E}_{\mathbf{s}}^{\mathrm{T}}
$$

2 The EOF analysis can be also applied to the temporal anomalies, $z_{i}(t)$, defined as:

$$
3 \quad z_{i}(t)=y_{i}(t)-\frac{1}{n} \sum_{\tau=1}^{n} y_{i}(\tau) .
$$

4 In this case, the eigenvectors are the spatial patterns (or EOFs). In all analyses, the statistical

5 significance of the first two EOFs was tested using a method based on Monte Carlo simulations

6 where 100 subsamples including $50 \%$ of the locations (i.e., Voronoi polygons) were randomly

7 selected and used to apply the EOFs. The resulting eigenvalues were used to build the $90 \%$

8 confidence interval. The EOF/PC pair of eigenvalue $k$ was assumed to be statistically significant

9 if the confidence interval does not overlap with that of eigenvalue $k+1$ [Hannachi et al., 2007]. 


\section{References}

Alcamo, J., M. Flörke, and M. Märker (2007), Future long-term changes in global water resources driven by socio-economic and climatic changes, Hydrol. Sci. J., 52(3), 247-275.

Bertoldi, G., C. Notarnicola, G. Leitinger, S. Endrizzi, M. Zebisch, S. D. Chiesa, and U. Tappeiner (2010), Topographical and ecohydrological controls on land surface temperature in an alpine catchment, Ecohydrology, 3, 189-204.

Beven, K. J., and M. J. Kirkby (1979), A physically based, variable contributing area model of basin hydrology, Hydrol. Sci. Bull., 24(1), 43-69.

Bosilovich, M. G., Y. C. Sud, S. D. Schubert, and G. K. Walker (2003), Numerical simulation of the large-scale North American monsoon water sources, J. Geophys. Res., 108, 8614, doi:10.1029/2002JD003095.

Cabral, M. C., L. Garrote, R. L. Bras, and D. Entekhabi (1992), A kinematic model of infiltration and runoff generation in layered and sloped soils, Adv. Water Resour., 15, 311-324.

Cai, X., Z.-L. Yang, C. H. David, G.-Y. Niu, and M. Rodell (2014), Hydrological evaluation of the Noah-MP land surface model for the Mississippi River Basin, J. Geophys. Res. Atmos., 119, 23-38, doi:10.1002/2013JD020792.

Camporese, M., C. Paniconi, M. Putti, and S. Orlandini (2010), Surface-subsurface flow modeling with path-based runoff routing, boundary condition-based coupling, and assimilation of multisource observation data, Water Resour. Res., 46, W02512, doi:10.1029/2008WR007536.

Camporese, M., E. Daly, P. E. Dresel, J. A. Webb (2014), Simplified modeling of catchmentscale evapotranspiration via boundary condition switching, Adv. Water Resour., 69, 95-105.

Camporese, M., G. Cassiani, R. Deiana, P. Salandin, and A. Binley (2015), Coupled and uncoupled hydrogeophysical inversions using ensemble Kalman filter assimilation of ERTmonitored tracer test data, Water Resour. Res., 51, doi:10.1002/2014WR016017.

Coblentz, D. D., and K. H. Riitters (2004), Topographic controls on the regional-scale biodiversity of the south-western USA, J. Biogeogr., 31, 1125-1138.

Dingman, S. L. (2002), Physical Hydrology, 2nd edn., Prentice Hall, Upper Saddle River, NJ.

Döll, P., F. Kaspar, and B. Lehner (2003), A global hydrological model for deriving water availability indicators: model tuning and validation, J. Hydrol., 270, 1-2, 105-134.

Dominguez, F., P. Kumar, and E. R. Vivoni (2008), Precipitation recycling variability and ecoclimatological stability - A study using NARR data. Part II: North American monsoon region, J. Climate., 21(20), 5187-5203. 
Dommenget, D., and M. Latif. (2002), A cautionary note on the interpretation of EOFs, $J$. Climate, 15, 216-225.

Duan, Q., S. Sorooshian and V. K. Gupta (1992), Effective and efficient global optimization for conceptual rainfall-runoff models, Water Resour. Res., 28(4), 1015-1031.

Ebel, B. A., B. B. Mirus, C. H. Heppner, J. E. VanderKwaak, and K. Loague (2009), First-order exchange coefficient coupling for simulating surface and subsurface interactions: parameter sensitivity and consistency with a physics-based approach, Hydrol. Process., 23, 1949-1959.

Espinoza Villar, J. C., J. Ronchail, J. L. Guyot, G. Cochonneau, F. Naziano, W. Lavado, E. De Oliveira, R. Pombosa, and P. Vauchel (2009), Spatio-temporal rainfall variability in the Amazon basin countries (Brazil, Peru, Bolivia, Colombia, and Ecuador), Int. J. Climatol., 29, 1574-1594.

Fensholt, R., I. Sanholt, and M. Schultz (2004), Evaluation of MODIS LAI, fAPAR and the relation between fAPAR and NDVI in a semiarid environment using in situ measurements, Remote Sens. Environ., 91, 490-507.

Forzieri, G., F. Castelli, and E. R. Vivoni (2011), Vegetation dynamics within the North American monsoon region, J. Climate, 24(6), 1763-1783.

Forzieri, G., E.R. Vivoni, and L. Feyen (2013), Ecosystem biophysical memory in the southwestern North America climate system, Environ. Res. Lett., 8(4): 044016, doi:10.1088/1748-9326/8/4/044016.

Forzieri, G., L. Feyen, R. Rojas, M. Flörke, F. Wimmer, and A. Bianchi (2014), Ensemble projections of future streamflow droughts in Europe, Hydrol. Earth Syst. Sci., 18, 85-108.

Gebremichael, M., E. R. Vivoni, C. J. Watts, and J. C. Rodriguez (2007), Sub-mesoscale spatiotemporal variability of North American monsoon rainfall over complex terrain. J. Climate, 20, 1751-1773.

Gochis, D. J., L. Brito-Castillo, and W. J. Shuttleworth (2006), Hydroclimatology of the North American monsoon region in northwest Mexico, J. Hydrol., 316, 53-70.

Goodrich, D. C., L. J. Lane, R. M. Shillito, S. N. Miller, K. H. Syed, and D. A. Woolhiser (1997), Linearity of basin response as a function of scale in a semiarid watershed, Water Resour. Res., 33(12), 2951-2965.

Grayson, R. B., G. Blöschl, A. W. Western, and T. A. McMahon (2002), Advances in the use of observed spatial patterns of catchment hydrological response, Adv. Water Resour., 25(8-12), 1313-1334.

Hannachi, A., I. T. Jolliffe, and D. B. Stephenson (2007), Empirical orthogonal functions and related techniques in atmospheric science: A review, Int. J. Climatol., 27, 1119-1152. 
Hamlet, A., and D. Lettenmaier (2005), Production of temporally consistent gridded precipitation and temperature fields for the continental United States, J. Hydrometeorol., 6(3), 330-336

Huang, F., and B. Li (2010), Assessing grain crop water productivity of China using a hydromodel-coupled-statistics approach: Part I: Method development and validation, Agr. Water Manage., 97(7), 1077-1092.

Instituto Nacional de Investigaciones Forestales, Agrícolas y Pecuarias (INIFAP) (2001), Inventario Nacional de Suelos, scale 1:250,000, Mexico City, Mexico.

Ivanov, V. Y. (2002), A continuous Real-time Interactive Basin Simulator (RIBS), M.S. thesis, R. M. Parsons Lab. for Water Resour. and Hydrodyn., Mass. Inst. of Technol., Cambridge.

Ivanov, V. Y., E. R. Vivoni, R. L. Bras, and D. Entekhabi (2004a), Catchment hydrologic response with a fully distributed triangulated irregular network model, Water Resour. Res., 40(11), W11102, doi:10.1029/2004WR003218.

Ivanov, V. Y., E. R. Vivoni, R. L. Bras, and D. Entekhabi (2004b), Preserving high-resolution surface and rainfall data in operational-scale basin hydrology: A fully distributed, physically based approach, J. Hydrol., 298(1-4), 80-111.

Ivanov, V. Y., R. L. Bras, and E. R. Vivoni (2008), Vegetation-hydrology dynamics in complex terrain of semiarid areas. I: A mechanistic approach to modeling dynamic feedbacks, Water Resour. Res., 44, W03429, doi:10.1029/2006WR005588.

Jawson, S. D., and J. D. Niemann (2007), Spatial patterns from EOF analysis of soil moisture at a large scale and their dependence on soil, land-use, and topographic properties, Adv. Water Resour., 30, 366-381.

Johnson, R. H., P. E. Ciesielski, B. D. McNoldy, P. J. Rogers, and R. K. Taft (2007), Multiscale variability of the flow during the North American Monsoon Experiment, J. Climate, 20, 16281648.

Karypis, G., and V. Kumar (1999), A fast and high quality multilevel scheme for partitioning irregular graphs, SIAM J. Scientific Comput., 20(1), 359-392.

Kim, G., and A. P. Barros (2002), Space-time characterization of soil moisture from passive microwave remotely sensed imagery and ancillary data, Remote Sens. Environ., 81, 93-403.

Kollet, S. J., and R. M. Maxwell (2008), Capturing the influence of groundwater dynamics on land surface processes using an integrated, distributed watershed model, Water Resour. Res., 44, W02402, doi:10.1029/2007WR006004. 
Kollet, S. J., R. M. Maxwell, C. S. Woodward, S. Smith, J. Vanderborght, H. Vereecken, and C. Simmer (2010), Proof of concept of regional scale hydrologic simulations at hydrologic resolution utilizing massively parallel computer resources, Water Resour. Res., 46, W04201, doi:10.1029/2009WR008730.

Koster, R. D., and S. P. P. Mahanama (2012), Land surface controls on hydroclimatic means and variability, J. Hydrometeor., 13, 1604-1620.

Lehner, B., P. Döll, J. Alcamo, T. Henrichs, and F. Kaspar (2006), Estimating the impact of global change on flood and drought risks in Europe: a continental, integrated analysis, Clim. Change, 75(3), 273-299.

Lettenmaier, C. H. Marshall, J. K. Entin, M. Pan, W. Shi, V. Koren, J. Meng, B. H. Ramsay and A. A. Bailey (2004), The multi-institution North American Land Data Assimilation System (NLDAS): Utilizing multiple GCIP products and partners in a continental distributed hydrological modeling system, J. Geophys. Res., 109, D07S90, doi:10.1029/2003JD003823.

Li, K. Y., M. T. Coe, and N. Ramankutty (2005), Investigation of hydrological variability in West Africa using land surface models, J. Climate, 18, 3173-3188.

Liu, Y. (2003), Spatial patterns of soil moisture connected to monthly-seasonal precipitation variability in a monsoon region, J. Geophys. Res., 108(D22), 8856, doi:10.1029/2002JD003124.

Liu, M., J. C. Adam, and A. F. Hamlet (2013a), Spatial-temporal variations of evapotranspiration and runoff/ precipitation ratios responding to the changing climate in the Pacific Northwest during 1921-2006, J. Geophys. Res. Atmos., 118, 380-394, doi:10.1029/2012JD018400.

Liu, J., A. Zhu, and C. Qin (2013b), Estimation of theoretical maximum speedup ratio for parallel computing of grid-based distributed hydrological models, Comput. Geosci., 60, 58-62.

Maneta, M. P., and N. L. Silverman (2013), A spatially distributed model to simulate water, energy, and vegetation dynamics using information from regional climate models, Earth Interact., 17, 1-44.

Mascaro, G., and E. R. Vivoni (2012), Utility of coarse and downscaled soil moisture products at L-band for hydrologic modeling at the catchment scale, Geophys. Res. Lett., 39, L10403, doi:10.1029/2012GL051809.

Mascaro, G., M. Piras, R. Deidda, and E. R. Vivoni (2013), Distributed hydrologic modeling of a sparsely monitored basin in Sardinia, Hydrol. Earth Syst. Sci., 17, 4143-4158.

Mascaro, G., E. R. Vivoni, D. J. Gochis, C. J. Watts, and J. C. Rodríguez (2014), Temporal downscaling and statistical analysis of rainfall across a topographic transect in northwest Mexico, J. Appl. Meteor. Climatol., 53, 910-927. 
Maxwell, R. M., M. Putti, S. Meyerhoff, J.-O. Delfs, I. M. Ferguson, V. Ivanov, J. Kim, O. Kolditz, S. J. Kollet, M. Kumar, S. Lopez, J. Niu, C. Paniconi, Y.-J. Park, M. S. Phanikumar, C. Shen, E. A. Sudicky and M. Sulis (2014), Surface-subsurface model intercomparison: A first set of benchmark results to diagnose integrated hydrology and feedbacks, Water Resour. Res., 50, 1531-1549.

Méndez-Barroso, L.A. (2014), Integration of remote sensing, field observations and modelling for ecohydrological studies in Sonora, Mexico. Ph.D. Dissertation in Geological Sciences, Arizona State University, Tempe, AZ, 196 pp.

Méndez-Barroso, L. A., and E. R. Vivoni (2010), Observed shifts in land surface conditions during the North American monsoon: Implications for a vegetation-rainfall feedback mechanism, J. Arid Environ., 74(5), 549-555.

Méndez-Barroso, L. A., E. R. Vivoni, A. Robles-Morua, G. Mascaro, E. A. Yépez, J. C. Rodríguez, C. J. Watts, J. Garatuza-Payán, and J. A. Saíz-Hernández (2014), A modeling approach reveals differences in evapotranspiration and its partitioning in two semiarid ecosystems in Northwest Mexico, Water Resour. Res., 50, 3229-3252.

Mitchell, K. E., D. Lohmann, P. R. Houser, E. F. Wood, J. C. Schaake, A. Robock, B. A. Cosgrove, J. Sheffield, Q. Duan, L. Luo, R. W. Higgins, R. T. Pinker, J. D. Tarpley, D. P.

Moreno, H. A., E. R. Vivoni, and D. J. Gochis (2013), Limits to flood forecasting in the Colorado Front Range for two summer convection periods using radar nowcasting and a distributed hydrologic model, J. Hydrometeor., 14(4), 1075-1097.

Nesbitt, S. W., D. J. Gochis, and T. J. Lang (2008), The diurnal cycle of clouds and precipitation along the Sierra Madre Occidental observed during NAME-2004: Implications for warm season precipitation estimation in complex terrain, J. Hydrometeor., 9, 728-743.

Newman, B. D., B. P. Wilcox, S. R. Archer, D. D. Breshears, C. N. Dahm, C. J. Duffy, N. G. McDowell, F. M. Phillips, B. R. Scanlon, and E. R. Vivoni (2006), Ecohydrology of waterlimited environments: A scientific vision, Water Resour. Res., 42, W06302, doi:10.1029/2005WR004141.

Pappenberger, F., J. Thielen, and M. Del Medico (2011), The impact of weather forecast improvements on large scale hydrology: analysing a decade of forecasts of the European Flood Alert System, Hydrol. Process., 25(7), 1099-1085.

Piras, M., G. Mascaro, R. Deidda, and E. R. Vivoni (2014), Quantification of hydrologic impacts of climate change in a Mediterranean basin in Sardinia, Italy, through high-resolution simulations, Hydrol. Earth Syst. Sci., in press.

Rigon, R., G. Bertoldi, and T. M. Over (2006), GEOtop: A distributed hydrological model with coupled water and energy budgets, J. Hydrometeor., 7, 371-388. 
Robles-Morua, A., E. R. Vivoni, and A. S. Mayer (2012), Distributed hydrologic modeling in northwest Mexico reveals the links between runoff mechanisms and evapotranspiration, $J$. Hydrometeor., 13, 785-807.

Rowe, A. K., S. A. Rutledge, T. J. Lang, P. E. Ciesielski, and S. M. Saleeby (2008), Elevationdependent trends in precipitation observed during NAME, Mon. Wea. Rev., 136, 4962-4979.

Ryu, D., T. J. Jackson, R. Bindlish, D. M. Le Vine, and M. Haken (2010), Soil moisture retrieval using a two-dimensional L-band synthetic aperture radiometer in a semiarid environment, IEEE Trans. Geosci. Remote Sens., 48(12), 4273-4284.

Ryu, Y., J. Verfaille, C. Macfarlane, H. Kobayashi, O. Sonnentag, R. Vargas, S. Ma, and D. Baldocchi (2012), Continuous observations of tree leaf area index at ecosystem scale using upward-pointing digital cameras, Remote Sens. Environ., 126, 115-125.

Saulnier, G. M., K. Beven, and C. Obled (1997), Including spatially variable effective soil depths in TOPMODEL, J. Hydrol., 202, 158-172.

Saxton, K. E., W. J. Rawls, J. S. Romberger and R. I. Papendick (1986), Estimating generalized soil-water characteristics from texture, Soil Sci. Soc. Amer. J., 50(4), 1031-1036.

Schewe, J., J. Heinkea, D. Gertena, I. Haddelandc, N. W. Arnelld, D. B. Clarke, R. Dankersf, S. Eisnerg, B. M. Feketeh, F. J. Colón-Gonzálezi, S. N. Goslingj, H. Kimk, X. Liul, Y. Masakim, F. T. Portmannn, Y. Satohp, T. Stackeq, Q. Tangl, Y. Wadar, D. Wissers, T. Albrechta, K. Frielera, F. Pionteka, L. Warszawskia, and P. Kabatt (2014), Multimodel assessment of water scarcity under climate change, Proc. Natl. Acad. Sci. U.S.A., 111 (9), 3245-3250.

Schmidt, R., S. Petrovic, A. Güntner, F. Barthelmes, J. Wünsch, and J. Kusche (2008), Periodic components of water storage changes from GRACE and global hydrology models, J. Geophys. Res., 113, B08419, doi:10.1029/2007JB005363.

Schuol, J., K. C. Abbaspour, H. Yang, R. Srinivasan, and A. J. B. Zehnder (2008), Modeling blue and green water availability in Africa, Water Resour. Res., 44, W07406, doi:10.1029/2007WR006609.

Seuffert, G., P. Gross, C. Simmer, and E. F. Wood (2002), The influence of hydrologic modeling on the predicted local weather: two-way coupling of a mesoscale weather prediction model and a land surface hydrologic model, J. Hydrometeor, 3, 505-523.

Shen, C., J. Niu, and M. S. Phanikumar (2013), Evaluating controls on coupled hydrologic and vegetation dynamics in a humid continental climate watershed using a subsurface-land surface processes model, Water Resour. Res., 49, 2552-2572, doi:10.1002/wrcr.20189.

Sulis, M., S. B. Meyerhoff, C. Paniconi, R. M. Maxwell, M. Putti, and S. J. Kollet (2010), A comparison of two physics-based numerical models for simulating surface water-groundwater interactions, Adv. Water Resour., 33(4), 456-467. 
Sulis, M., C. Paniconi, C. Rivard, R. Harvey, and D. Chaumont (2011), Assessment of climate change impacts at the catchment scale with a detailed hydrological model of surface-subsurface interactions and comparison with a land surface model, Water Resour. Res., 47, W01513, doi:10.1029/2010WR009167.

Syed, T. H., V. Lakshmi, E. Paleologos, D. Lohmann, K. Mitchell, and J. S. Famiglietti (2004), Analysis of process controls in land surface hydrological cycle over the continental United States, J. Geophys. Res., 109, D22105, doi:10.1029/2004JD004640.

Trabucco, A., R. J. Zomer, D. A. Bossio, O. van Straaten, and L. V. Verchot (2008), Climate change mitigation through afforestation/reforestation: A global analysis of hydrologic impacts with four case studies, Agric. Ecosyst. Environ., 126, 1-2, 81-97.

Vivoni, E. R., V. Y. Ivanov, R. L. Bras, and D. Entekhabi (2004), Generation of triangulated irregular networks based on hydrological similarity, J. Hydrol. Eng., 9(4), 288-302.

Vivoni, E. R., V. Y. Ivanov, R. L. Bras, and D. Entekhabi (2005), On the effects of triangulated terrain resolution on distributed hydrologic model response, Hydrol. Process., 19(11), 21012122.

Vivoni, E. R., H. A. Gutiérrez-Jurado, C. A. Aragón, L. A. Méndez-Barroso, A. J. Rinehart, R. L. Wyckoff, J. C. Rodríguez, C. J. Watts, J. D. Bolten, V. Lakshmi, and T. J. Jackson (2007a), Variation of hydrometeorological conditions along a topographic transect in northwestern Mexico during the North American monsoon, J. Climate, 20(9), 1792-1809.

Vivoni, E. R., D. Entekhabi, R. L. Bras, and V. Y. Ivanov (2007b), Controls on runoff generation and scale-dependence in a distributed hydrologic model, Hydrol. Earth Syst. Sci., 11(5), 16831701 .

Vivoni, E. R., Rinehart, A. J., Méndez-Barroso, L. A., Aragón, C. A., Bisht, G., Cardenas, M. B., Engle, E., Forman, B. A., Frisbee, M. D., Gutiérrez-Jurado, H. A., Hong, S.-h., Mahmood, T. H., Tai, K. and Wyckoff, R. L. (2008), Vegetation controls on soil moisture distribution in the Valles Caldera, New Mexico, during the North American monsoon, Ecohydrol., 1, 225-238.

Vivoni, E. R., J. C. Rodríguez, and C. J. Watts (2010a), On the spatiotemporal variability of soil moisture and evapotranspiration in a mountainous basin within the North American monsoon region, Water Resour. Res., 46, W02509, doi:10.1029/2009WR008240.

Vivoni, E. R., J. C. Watts, J. C. Rodríguez, J. Garatuza-Payan, L. A. Méndez-Barroso, J. A. SaizHernández (2010b), Improved land-atmosphere relations through distributed footprint sampling in a subtropical scrubland during the North American monsoon, J. Arid Environ., 74(5), 579584 . 
1 Vivoni, E. R., G. Mascaro, S. Mniszewski, P. Fasel, E. P. Springer, V. Y. Ivanov, and R. L. Bras

2 (2011), Real-world hydrologic assessment of a fully-distributed hydrological model in a parallel 3 computing environment, J. Hydrol., 409, 483-496.

Vivoni, E. R. (2012a), Spatial patterns, processes and predictions in ecohydrology: Integrating technologies to meet the challenge, Ecohydrology, 5(3), 235-241.

Vivoni, E. R. (2012b), Diagnosing seasonal vegetation impacts on evapotranspiration and its partitioning at the catchment scale during SMEX04-NAME, J. Hydrometeor, 13, 1631-1638.

Vörösmarty, C. J., P. Green, J. Salisbury, and R. B. Lammers (2000), Global water resources: Vulnerability from climate change and population growth, Science, 289(5477), 284-288.

Wood, A. W., E. P. Maurer, A. Kumar, and D. Lettenmaier (2002), Long-range experimental hydrologic forecasting for the eastern United States, J. Geophys. Res., 107(D20), 4429, doi:10.1029/2001JD000659.

Wood, E. F., J. K. Roundy, T. J. Troy, L. P. H. van Beek, M. F. P. Bierkens, E. Blyth, A. de Roo, P. Döll, M. Ek, J. Famiglietti, D. Gochis, N. van de Giesen, P. Houser, P. R. Jaffé, S. Kollet, B. Lehner, D. P. Lettenmaier, C. Peters-Lidard, M. Sivapalan, J. Sheffield, A. Wade, and P. Whitehead (2011), Hyperresolution global land surface modeling: Meeting a grand challenge for monitoring Earth's terrestrial water, Water Resour. Res., 47, W05301, doi:10.1029/2010WR010090.

Xiang, T., E. R. Vivoni, and D. J. Gochis (2014), Seasonal evolution of ecohydrological controls on land surface temperature over complex terrain, Water Resour. Res., 50, 3852-3874.

Yilmaz, M. T., E. R. Hunt, L. D. Goins, S. L. Ustin, V. C. Venderbilt, and T. J. Jackson (2008), Vegetation water content during SMEX04 from ground data and Landsat 5 Thematic Mapper imagery, Remote Sens. Environ., 112(2), 350-362. 


\section{Table Captions}

2 Table 1. Percentage of basin area $\left(A_{f}\right)$ of the RSM covered by each land cover and soil class,

3 including the ID used in the text.

5 Table 2. Datasets used in the hyperresolution hydrologic simulations. Sources are North

6 American Land Data Assimilation System (NLDAS), Comisión Estatal del Agua (CEA),

7 Comisión Nacional del Agua (CONAGUA), Arizona State University and Universidad de

8 Sonora (ASU-UNISON), Moderate Resolution Imaging Spectroradiometer (MODIS) and 2-D

9 Synthetic Aperture Radiometer (2D-STAR). The types of data are ground observations (GO), 10 remotely-sensed products (RS), or reanalysis products (RP). The variables are precipitation $(\mathrm{P})$,

11 atmospheric pressure (PA), incoming solar radiation (IS), relative humidity (RH), air temperature

12 (TA), wind speed (WS), latent heat (LH), soil moisture (SM), land surface temperature (LST),

13 leaf area index (LAI), normalized difference vegetation index (NDVI), fraction of

14 photosynthetically active radiation (fPAR) and albedo (AL).

$1712 \mathrm{~N}$ ), elevation $(z)$, land cover (LC) and soil class, percentage of sand and silt measured from a

18 site sample and from the ISRIC-WISE database and model calibration (Cal.) and validation

19 (Val.) years (for period 1 June to 30 September). NA is Not Available.

23 Table 5. Performance metrics for surface SM calibration and, in parentheses, validation for

24 station simulations (top) and basin simulation (bottom). Mean and standard deviation (STD)

25 across all stations are reported in italics. Metrics are Bias, $B=\bar{S}-\bar{O}$, Mean Absolute Error, 
$1 \quad M A E=\frac{1}{N} \sum_{j=1}^{N}\left|S_{j}-O_{j}\right|$ and Correlation Coefficient,

$2 C C=\left\{\sum_{j=1}^{N}\left(O_{j}-\bar{O}\right)\left(S_{j}-\bar{S}\right)\right\} /\left\{\left[\sum_{j=1}^{N}\left(O_{j}-\bar{O}\right)^{2}\right]^{0.5}\left[\sum_{j=1}^{N}\left(S_{j}-\bar{S}\right)^{2}\right]^{0.5}\right\}$, where $S_{j}$ and $O_{j}$ are the

3 simulated and observed variables for $j=1, \ldots, N$ time steps and $\bar{S}$ and $\bar{O}$ are their temporal

4 means.

5

6 Table 6. Performance metrics of the comparisons of SM from 2D-STAR and LST from MODIS

7 with the model outputs (top) and station observations (bottom). Mean and standard deviation

8 (STD) across all days are reported in italics. NA is Not Available.

11 properties at the monthly and daily (italics) time scales. The percentage of total variance

12 explained by each EOF is shown. Dashes represent correlations that were not performed. 13

14 Table 8. Correlation coefficients (CCs) between EOFs of evapotranspiration (ET/P) and runoff

$15(\mathrm{Q} / \mathrm{P})$ ratios with model forcings and basin properties at the monthly scales for spatial and 16 temporal (italics) anomalies. The percentage of total variance explained by each EOF is shown. 
1

\begin{tabular}{cccccc}
\hline Land Cover Class & ID & $\begin{array}{c}\boldsymbol{A}_{\boldsymbol{f}} \\
{[\mathbf{\%}]}\end{array}$ & Soil Class & ID & $\begin{array}{c}\boldsymbol{A}_{\boldsymbol{f}} \\
{[\mathbf{\%}]}\end{array}$ \\
\hline & & & & & \\
Water Body & WB & $<0.1$ & Lithosol Coarse - Low Elevation & LC-LE & 22.0 \\
Bare Soil & $\mathrm{BS}$ & $<0.1$ & Lithosol Coarse - High Elevation & LC-HE & 12.4 \\
Shrubland & $\mathrm{S}$ & 0.2 & Lithosol Medium & LM & 8.6 \\
Grassland & G & 8.3 & Phaeozem Medium & PM & 9.2 \\
Riparian Mesquite & EM & 4.6 & Regosol Coarse & RC & 11.0 \\
Riparian Woodland & RW & 0.1 & Regosol Medium & RM & 17.0 \\
Sparse Woodland & SW & 38.1 & Xerosol Medium & XM & 14.1 \\
Evergreen Woodland & EW & 2.9 & Fluvisol Coarse & FC & 1.3 \\
Subtropical Scrubland & SS & 45.7 & Fluvisol Medium & FM & 2.5 \\
Agriculture & A & $<0.1$ & Yemesol Coarse & YC & 1.9 \\
& & & & & \\
\hline
\end{tabular}

Table 1. Percentage of basin area $\left(A_{f}\right)$ of the RSM covered by each land cover and soil class,

4 including the ID used in the text. 


\begin{tabular}{|c|c|c|c|c|c|c|}
\hline & Source & Type & Variables & Resolution & Reference & Use \\
\hline & NLDAS & $\begin{array}{l}\mathrm{RP}, \\
\mathrm{RS}\end{array}$ & $\begin{array}{l}\text { P, PA, IS, } \\
\text { RH, TA, } \\
\text { WS }\end{array}$ & $12 \mathrm{~km}, 1 \mathrm{~h}$ & Mitchell et al. [2004] & Model forcings \\
\hline & CEA & GO & $\begin{array}{c}\text { P, PA, RH, } \\
\text { TA, WS }\end{array}$ & Station, Daily & & $\begin{array}{l}\text { NLDAS } \\
\text { correction }\end{array}$ \\
\hline & CONAGUA & GO & $\mathrm{P}$ & Station, Daily & Vivoni et al. [2007a]; & $\begin{array}{l}\text { NLDAS } \\
\text { correction }\end{array}$ \\
\hline & $\begin{array}{c}\text { ASU- } \\
\text { UNISON }\end{array}$ & GO & $\begin{array}{l}\text { P, SM, PA, } \\
\text { IS, RH, TA, } \\
\text { WS, LH }\end{array}$ & Station, $1 \mathrm{~h}$ & $\begin{array}{l}\text { Robles-Morua et al. } \\
\text { [2012] }\end{array}$ & $\begin{array}{c}\text { NLDAS } \\
\text { correction; } \\
\text { Model } \\
\text { calibration and } \\
\text { validation }\end{array}$ \\
\hline & & & LST & 1000 m, Daily & & $\begin{array}{c}\text { Model } \\
\text { validation }\end{array}$ \\
\hline & MODIS & RS & $\begin{array}{c}\text { NDVI } \\
\text { LAI, fPAR } \\
\text { AL }\end{array}$ & $\begin{array}{c}250 \mathrm{~m}, \\
16 \text { day Composite } \\
250 \mathrm{~m}, \\
8 \text { day Composite } \\
1000 \mathrm{~m}, \\
16 \text { day Composite }\end{array}$ & http://modis.gsfc.nasa.gov/ & $\begin{array}{l}\text { Derivation of } \\
\text { vegetation } \\
\text { parameters }\end{array}$ \\
\hline & 2D-STAR & RS & SM & 800 m, Daily & Ryu et al. [2010] & $\begin{array}{l}\text { Model } \\
\text { validation }\end{array}$ \\
\hline $\begin{array}{l}1 \\
2\end{array}$ & \multicolumn{6}{|c|}{ Table 2. Datasets used in the hyperresolution hydrologic simulations. Sources are North } \\
\hline 3 & \multicolumn{6}{|c|}{ American Land Data Assimilation System (NLDAS), Comisión Estatal del Agua (CEA), } \\
\hline 4 & \multicolumn{6}{|c|}{ Comisión Nacional del Agua (CONAGUA), Arizona State University and Universidad de } \\
\hline 5 & \multicolumn{6}{|c|}{ Sonora (ASU-UNISON), Moderate Resolution Imaging Spectroradiometer (MODIS) and 2-D } \\
\hline 6 & \multicolumn{6}{|c|}{ Synthetic Aperture Radiometer (2D-STAR). The types of data are ground observations (GO), } \\
\hline 7 & \multicolumn{6}{|c|}{ remotely-sensed products $(\mathrm{RS})$, or reanalysis products $(\mathrm{RP})$. The variables are precipitation $(\mathrm{P})$, } \\
\hline 8 & \multicolumn{6}{|c|}{ atmospheric pressure (PA), incoming solar radiation (IS), relative humidity $(\mathrm{RH})$, air temperature } \\
\hline 9 & \multicolumn{6}{|c|}{ (TA), wind speed (WS), latent heat (LH), soil moisture (SM), land surface temperature (LST), } \\
\hline 10 & \multicolumn{6}{|c|}{ leaf area index (LAI), normalized difference vegetation index (NDVI), fraction of } \\
\hline 1 & \multicolumn{6}{|c|}{ photosynthetically active radiation (fPAR) and albedo (AL). } \\
\hline
\end{tabular}




\begin{tabular}{|c|c|c|c|c|c|c|c|c|c|}
\hline Station & $\begin{array}{c}\mathbf{E} \\
{[\mathbf{m}]}\end{array}$ & $\begin{array}{c}\mathbf{N} \\
{[\mathbf{m}]}\end{array}$ & $\begin{array}{c}\boldsymbol{z} \\
{[\mathbf{m}]}\end{array}$ & $\begin{array}{c}\text { LC } \\
\text { Class }\end{array}$ & $\begin{array}{c}\text { Soil } \\
\text { Class }\end{array}$ & $\begin{array}{c}\text { Sample } \\
\% \text { sand/ } \\
\% \text { silt }\end{array}$ & $\begin{array}{l}\text { ISRIC- } \\
\text { WISE } \\
\% \text { sand/ } \\
\% \text { silt } \\
\end{array}$ & $\begin{array}{l}\text { Cal. } \\
\text { Year }\end{array}$ & $\begin{array}{l}\text { Val. } \\
\text { Year }\end{array}$ \\
\hline 130 & 531465 & 3323298 & 708 & SW & $\mathrm{RC}$ & $91 / 7$ & $83 / 10$ & 2004 & 2007 \\
\hline 132 & 546347 & 3314298 & 878 & SS & LC-LE & $70 / 25$ & $74 / 18$ & 2004 & 2007 \\
\hline 133 & 539130 & 3305014 & 624 & SW & $\mathrm{RM}$ & $74 / 19$ & $44 / 36$ & 2005 & 2007 \\
\hline 143 & 542590 & 3356533 & 947 & SS & $\mathrm{FC}$ & $77 / 15$ & $79 / 12$ & 2004 & 2005 \\
\hline 144 & 530134 & 3341169 & 778 & $\mathrm{SS}$ & FM & $36 / 35$ & $35 / 27$ & 2007 & 2005 \\
\hline 146 & 551091 & 3315638 & 1377 & EW & LC-HE & $71 / 17$ & $74 / 19$ & 2004 & 2007 \\
\hline 147 & 544811 & 3290182 & 632 & SS & YC & NA & $84 / 10$ & 2004 & 2006 \\
\hline 151 & 542954 & 3387967 & 1419 & $\mathrm{RM}$ & $\mathrm{XM}$ & NA & $56 / 18$ & 2007 & 2009 \\
\hline 154 & 530064 & 3264545 & 419 & SW & PM & NA & $83 / 10$ & 2007 & 2008 \\
\hline
\end{tabular}

2 Table 3. Station characteristics, including UTM coordinates (Easting, E, and Northing, N; zone

$312 \mathrm{~N})$, elevation $(z)$, land cover (LC) and soil class, percentage of sand and silt measured from a

4 site sample and from the ISRIC-WISE database and model calibration (Cal.) and validation

5 (Val.) years (for period 1 June to 30 September). NA is Not Available. 


\begin{tabular}{cccccccccc}
\hline ID & Station & $\begin{array}{c}\boldsymbol{K}_{\boldsymbol{s}} \\
{[\mathbf{m m} / \mathbf{h}]}\end{array}$ & $\begin{array}{c}\boldsymbol{\theta}_{\boldsymbol{s}} \\
{\left[\mathbf{m}^{\mathbf{3}} / \mathbf{m}^{\mathbf{3}}\right]}\end{array}$ & $\begin{array}{c}\boldsymbol{\theta}_{\boldsymbol{r}} \\
{\left[\mathbf{m}^{\mathbf{3}} / \mathbf{m}^{\mathbf{3}}\right]}\end{array}$ & $\begin{array}{c}\boldsymbol{\theta}^{*} \boldsymbol{e}^{\mathbf{3}} \\
{\left[\mathbf{m}^{\mathbf{3}} \mathbf{m}^{\mathbf{3}}\right]}\end{array}$ & $\begin{array}{c}\boldsymbol{\theta}^{*}{ }_{\boldsymbol{t}} \\
{\left[\mathbf{m}^{\mathbf{3}} / \mathbf{m}^{\mathbf{3}}\right]}\end{array}$ & $\begin{array}{c}\boldsymbol{m} \\
{[-]}\end{array}$ & $\begin{array}{c}\boldsymbol{f} \\
{\left[\mathbf{m m}^{-\mathbf{1}} \mathbf{]}\right.}\end{array}$ & $\begin{array}{c}\boldsymbol{n} \\
{\left[\mathbf{m}^{\mathbf{3}} / \mathbf{m}^{\mathbf{3}}\right]}\end{array}$ \\
\hline LC-LE & 132 & 32.4 & 0.40 & 0.01 & 0.07 & 0.06 & 2.0 & $8 \times 10^{-4}$ & 0.42 \\
LC-HE & 146 & 32.4 & 0.40 & 0.01 & 0.08 & 0.08 & 0.6 & $8 \times 10^{-3}$ & 0.42 \\
LM & NA & 6.2 & 0.47 & 0.01 & 0.07 & 0.06 & 2.0 & $8 \times 10^{-4}$ & 0.49 \\
PM & 154 & 15.0 & 0.49 & 0.01 & 0.19 & 0.19 & 2.0 & $8 \times 10^{-4}$ & 0.51 \\
RC & 130 & 49.1 & 0.38 & 0.002 & 0.04 & 0.04 & 0.8 & $3 \times 10^{-4}$ & 0.40 \\
RM & 133 & 8.3 & 0.47 & 0.002 & 0.24 & 0.24 & 2.0 & $3 \times 10^{-4}$ & 0.49 \\
XM & 151 & 3.9 & 0.47 & 0.01 & 0.28 & 0.28 & 2.0 & $6 \times 10^{-4}$ & 0.49 \\
FC & 143 & 33.6 & 0.40 & 0.03 & 0.28 & 0.28 & 0.6 & $5 \times 10^{-2}$ & 0.42 \\
FM & 144 & 5.0 & 0.51 & 0.05 & 0.26 & 0.26 & 2.0 & $9 \times 10^{-4}$ & 0.53 \\
YC & 147 & 49.1 & 0.38 & 0.002 & 0.19 & 0.19 & 1.5 & $9 \times 10^{-4}$ & 0.40 \\
\hline
\end{tabular}

Table 4. Model parameters for the soil classes. NA is Not Available. 


\begin{tabular}{cccc}
\hline Station & $\begin{array}{c}\mathbf{B} \\
{\left[\mathbf{m}^{\mathbf{3}} / \mathbf{m}^{\mathbf{3}}\right]}\end{array}$ & $\begin{array}{c}\text { MAE } \\
{\left[\mathbf{m}^{\mathbf{3}} / \mathbf{m}^{\mathbf{3}}\right]}\end{array}$ & $\begin{array}{c}\mathbf{C C} \\
{[-]}\end{array}$ \\
\hline \multicolumn{4}{c}{ Station simulations } \\
130 & $0.006(-0.008)$ & $0.013(0.017)$ & $0.937(0.882)$ \\
132 & $0.003(-0.007)$ & $0.016(0.016)$ & $0.907(0.921)$ \\
133 & $0.002(-0.002)$ & $0.015(0.016)$ & $0.947(0.928)$ \\
143 & $-0.027(-0.062)$ & $0.033(0.062)$ & $0.852(0.940)$ \\
144 & $-0.001(-0.024)$ & $0.021(0.038)$ & $0.948(0.839)$ \\
146 & $0.022(-0.004)$ & $0.024(0.019)$ & $0.944(0.942)$ \\
147 & $-0.002(0.006)$ & $0.012(0.012)$ & $0.912(0.953)$ \\
151 & $-0.009(-0.016)$ & $0.026(0.026)$ & $0.910(0.887)$ \\
154 & $0.003(0.010)$ & $0.015(0.029)$ & $0.899(0.835)$ \\
Mean & $-0.0003(-0.012)$ & $0.019(0.026)$ & $0.917(0.903)$ \\
STD & $0.013(0.021)$ & $0.007(0.016)$ & $0.031(0.044)$
\end{tabular}

Basin simulation

$\begin{array}{cccc}130 & 0.027(0.049) & 0.033(0.059) & 0.822(0.793) \\ 132 & 0.106(0.111) & 0.117(0.121) & 0.648(0.837) \\ 133 & 0.024(0.058) & 0.034(0.060) & 0.826(0.912) \\ 143 & 0.052(-0.020) & 0.076(0.061) & 0.592(0.817) \\ 144 & 0.025(-0.016) & 0.043(0.046) & 0.798(0.757) \\ 146 & 0.053(0.047) & 0.058(0.081) & 0.687(0.634) \\ 147 & 0.032(0.009) & 0.036(0.037) & 0.691(0.490) \\ 151 & -0.017(0.007) & 0.038(0.045) & 0.782(0.707) \\ 154 & 0.005(0.006) & 0.027(0.029) & 0.887(0.831) \\ \text { Mean } & 0.034(0.028) & 0.051(0.060) & 0.748(0.753) \\ \text { STD } & 0.035(0.042) & 0.029(0.028) & 0.097(0.127)\end{array}$

1

2 Table 5. Performance metrics for surface SM calibration and, in parentheses, validation for

3 station simulations (top) and basin simulation (bottom). Mean and standard deviation (STD)

4 across all stations are reported in italics. Metrics are Bias, $B=\bar{S}-\bar{O}$, Mean Absolute Error,

$5 \quad M A E=\frac{1}{N} \sum_{j=1}^{N}\left|S_{j}-O_{j}\right|$ and Correlation Coefficient,

$6 \quad C C=\left\{\sum_{j=1}^{N}\left(O_{j}-\bar{O}\right)\left(S_{j}-\bar{S}\right)\right\} /\left\{\left[\sum_{j=1}^{N}\left(O_{j}-\bar{O}\right)^{2}\right]^{0.5}\left[\sum_{j=1}^{N}\left(S_{j}-\bar{S}\right)^{2}\right]^{0.5}\right\}$, where $S_{j}$ and $O_{j}$ are the 
1 simulated and observed variables for $j=1, \ldots, N$ time steps and $\bar{S}$ and $\bar{O}$ are their temporal 2 means. 


\begin{tabular}{ccccccc}
\hline $\begin{array}{c}\text { Day } \\
\text { of August } \\
\mathbf{2 0 0 4}\end{array}$ & $\begin{array}{c}\text { SM } \\
{[\%]}\end{array}$ & $\begin{array}{c}\text { LST } \\
{\left[{ }^{\circ} \mathbf{C}\right]}\end{array}$ & $\begin{array}{c}\text { SM } \\
{\left[\mathbf{m}^{3} / \mathbf{m}^{3}\right]}\end{array}$ & $\begin{array}{c}\text { LST } \\
{\left[{ }^{\circ} \mathbf{C}\right]}\end{array}$ & $\begin{array}{c}\text { SM } \\
{[-]}\end{array}$ & $\begin{array}{c}\text { LST } \\
{[-]}\end{array}$ \\
\hline 7 & 0.028 & 0.7 & 0.041 & 2.9 & 0.257 & 0.702 \\
8 & 0.070 & -3.6 & 0.079 & 4.5 & 0.202 & 0.529 \\
24 & 0.028 & NA & 0.034 & NA & 0.117 & NA \\
25 & -0.015 & -0.1 & 0.036 & 4.0 & 0.069 & 0.679 \\
26 & 0.004 & -5.4 & 0.025 & 5.6 & 0.113 & 0.778 \\
Mean & 0.023 & -2.100 & 0.043 & 4.250 & 0.152 & 0.672 \\
STD & 0.032 & 2.886 & 0.021 & 1.121 & 0.076 & 0.104 \\
\multicolumn{7}{c}{ Model vs. remotely-sensed products } \\
7 & -0.016 & 5.2 & 0.033 & 5.9 & 0.040 & 0.535 \\
8 & -0.018 & -4.5 & 0.040 & 4.5 & 0.634 & 0.537 \\
24 & 0.006 & NA & 0.039 & NA & -0.340 & NA \\
25 & -0.012 & 3.1 & 0.045 & 9.4 & -0.598 & -0.050 \\
26 & -0.013 & -1.8 & 0.051 & 6.8 & -0.642 & 0.155 \\
Mean & -0.011 & 0.500 & 0.042 & 6.650 & -0.181 & 0.294 \\
STD & 0.010 & 4.440 & 0.007 & 2.063 & 0.530 & 0.291 \\
\hline
\end{tabular}

1

2 Table 6. Performance metrics of the comparisons of surface SM from 2D-STAR and LST from

3 MODIS with the model outputs (top) and station observations (bottom). Mean and standard

4 deviation (STD) across all days are reported in italics. NA is Not Available. 
2 Table 7. Correlation coefficients (CCs) between EOFs of model forcings, outputs and basin

3 properties at the monthly and daily (italics) time scales. The percentage of total variance

4 explained by each EOF is shown. Dashes represent correlations that were not performed. 


\begin{tabular}{|c|c|c|c|c|}
\hline & $\begin{array}{l}\text { EOF1 } \\
\text { ET/P }\end{array}$ & $\begin{array}{l}\text { EOF2 } \\
\text { ET/P } \\
\end{array}$ & $\begin{array}{c}\text { EOF1 } \\
\text { Q/P }\end{array}$ & $\begin{array}{c}\text { EOF2 } \\
\text { Q/P }\end{array}$ \\
\hline $\begin{array}{c}\text { Variance } \\
\text { explained }\end{array}$ & $\begin{array}{l}55 \% \\
58 \% \\
\end{array}$ & $\begin{array}{l}19 \% \\
16 \% \\
\end{array}$ & $\begin{array}{l}70 \% \\
72 \% \\
\end{array}$ & $\begin{array}{c}10 \% \\
3 \% \\
\end{array}$ \\
\hline \multicolumn{5}{|c|}{ Basin Properties } \\
\hline$z$ & $\begin{array}{l}0.15 \\
0.29\end{array}$ & $\begin{array}{l}-0.36 \\
-0.34\end{array}$ & $\begin{array}{c}0.07 \\
-0.29\end{array}$ & $\begin{array}{r}-0.35 \\
0.04\end{array}$ \\
\hline$\beta$ & $\begin{array}{l}-0.33 \\
-0.21\end{array}$ & $\begin{array}{c}0.07 \\
-0.12\end{array}$ & $\begin{array}{c}-0.24 \\
0.21\end{array}$ & $\begin{array}{l}0.06 \\
0.17\end{array}$ \\
\hline$\lambda$ & $\begin{array}{l}0.36 \\
0.27\end{array}$ & $\begin{array}{l}0.01 \\
0.19\end{array}$ & $\begin{array}{c}0.29 \\
-0.26\end{array}$ & $\begin{array}{l}-0.07 \\
-0.14\end{array}$ \\
\hline $\boldsymbol{K}_{s}$ & $\begin{array}{l}-0.04 \\
-0.08\end{array}$ & $\begin{array}{l}0.25 \\
0.23\end{array}$ & $\begin{array}{r}-0.06 \\
0.08\end{array}$ & $\begin{array}{c}-0.06 \\
0.30\end{array}$ \\
\hline EOF1 P & $\begin{array}{l}\text { Mode } \\
0.14 \\
0.35\end{array}$ & $\begin{array}{c}\text { Forcing } \\
-0.75 \\
-0.29\end{array}$ & $\begin{array}{l}-0.01 \\
-0.36\end{array}$ & $\begin{array}{l}-0.23 \\
-0.02\end{array}$ \\
\hline EOF2 P & $\begin{array}{l}0.07 \\
0.21\end{array}$ & $\begin{array}{l}-0.08 \\
-0.66\end{array}$ & $\begin{array}{l}0.05 \\
0.15\end{array}$ & $\begin{array}{l}-0.26 \\
-0.27\end{array}$ \\
\hline EOF1 VF & $\begin{array}{l}0.14 \\
0.28\end{array}$ & $\begin{array}{l}0.48 \\
0.22\end{array}$ & $\begin{array}{c}0.26 \\
-0.23\end{array}$ & $\begin{array}{r}-0.04 \\
0.12\end{array}$ \\
\hline EOF2 VF & $\begin{array}{l}0.15 \\
0.23\end{array}$ & $\begin{array}{l}-0.41 \\
-0.48\end{array}$ & $\begin{array}{c}0.11 \\
-0.21\end{array}$ & $\begin{array}{l}-0.34 \\
-0.21\end{array}$ \\
\hline
\end{tabular}

1

2 Table 8. Correlation coefficients (CCs) between EOFs of evapotranspiration (ET/P) and runoff

$3(\mathrm{Q} / \mathrm{P})$ ratios with model forcings and basin properties at the monthly scales for spatial and

4 temporal (italics) anomalies. The percentage of total variance explained by each EOF is shown. 


\section{Figure Captions}

2 Fig. 1. (a) Location of the RSM basin in Sonora, Mexico. (b) Three-dimensional representation

3 of the watershed boundary, terrain characteristics and channel network of the RSM.

5 Fig. 2. (a) Land cover and (b) soil class maps of the RSM basin with location of the stations used

6 for testing the hydrologic model. (c) Channel network and floodplain boundaries represented in

7 the model. Acronyms of the soil and land cover classes are described in Table 1.

10 along with 2D-STAR retrievals at the co-located pixel (where available). Insets show scatterplots

11 between observed and simulated LST $\left({ }^{\circ} \mathrm{C}\right)$. Data gaps are due to missing observations or poor 12 data quality.

Fig. 4. (a, b) Comparison of spatial patterns of simulated and retrieved (2D-STAR) surface (top 5 cm) SM on 8 and 25 August 2004. (c, d) Comparison of spatial patterns of simulated and estimated (MODIS) LST on the same days. Model outputs are for the overpass times and are resampled at same resolution ( $800 \mathrm{~m}$ for 2D-STAR and $1000 \mathrm{~m}$ for MODIS). White areas represent missing data. Circles of different size depict the surface SM and LST measured by individual stations at coincident times.

Fig. 5. Basin-averaged time series of (a) daily total P, (b) daily average NDVI, (c) daily average surface (top $5 \mathrm{~cm}$ ) and root zone (top $1 \mathrm{~m}$ ) SM, (d) daily average LST, (e) daily total ET, and (f) daily total Q at the outlet (expressed as depth to facilitate comparison with other fluxes). Summer (1 July to 30 September) and winter (1 December to 28 February) seasons are indicated during the simulation period from 1 January 2004 to 31 December 2010. 
2 Fig. 6. Spatial distribution of the temporal average over the simulation period of (a, b) P and (c,

3 d) surface SM and (e, f) ET in the summer and winter periods. Contour lines of seasonal

4 precipitation totals are also shown in $(a, b)$.

5

Fig. 7. First two EOFs of (a) P and (b) VF at the monthly scale, with the percentage of the

7 explained variance indicated.

8

Fig. 8. Time series of the monthly averaged PCs associated with the first two EOFs at the

10 monthly scale of (a) P, (b) VF, (c) surface SM, (d) ET and (e) Q.

11

Fig. 9. Same as Fig. 7, but for (a) surface SM, (b) ET and (c) Q.

13

Fig. 10. Time series of the daily averaged PCs associated with the first two EOFs at the daily scale in summer for (a) P, (b) VF, (c) surface SM, (d) ET and (e) Q.

Fig. 11. Spatial distribution of (a) evapotranspiration ratio $(E T / P)$ and $(b)$ runoff ratio $(Q / P)$ 18 averaged over the summer months in the simulation.

Fig. 12. First two EOFs of $E T / P$ and $Q / P$ at the monthly scale for the spatial $(a, b)$ and temporal 21 (c, d) anomalies, with the percentage of explained variance indicated.

Fig. 13. Time series of the monthly averaged PCs associated with the first two EOFs at the 24 monthly scale in the summer for (a) ET/P and (b) Q/P. 


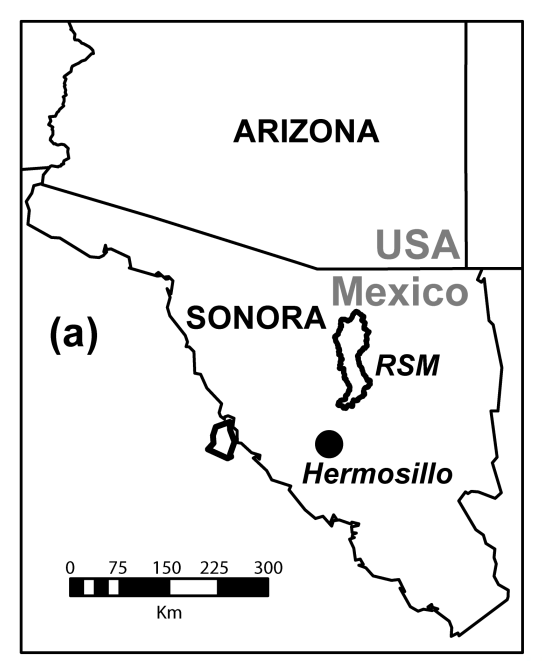

(b)

\section{Elevation [m]}
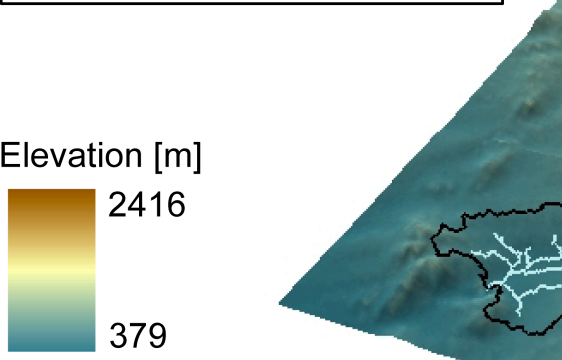

1

3 Fig. 1. (a) Location of the RSM basin in Sonora, Mexico. (b) Three-dimensional representation

4 of the watershed boundary, terrain characteristics and channel network of the RSM. 

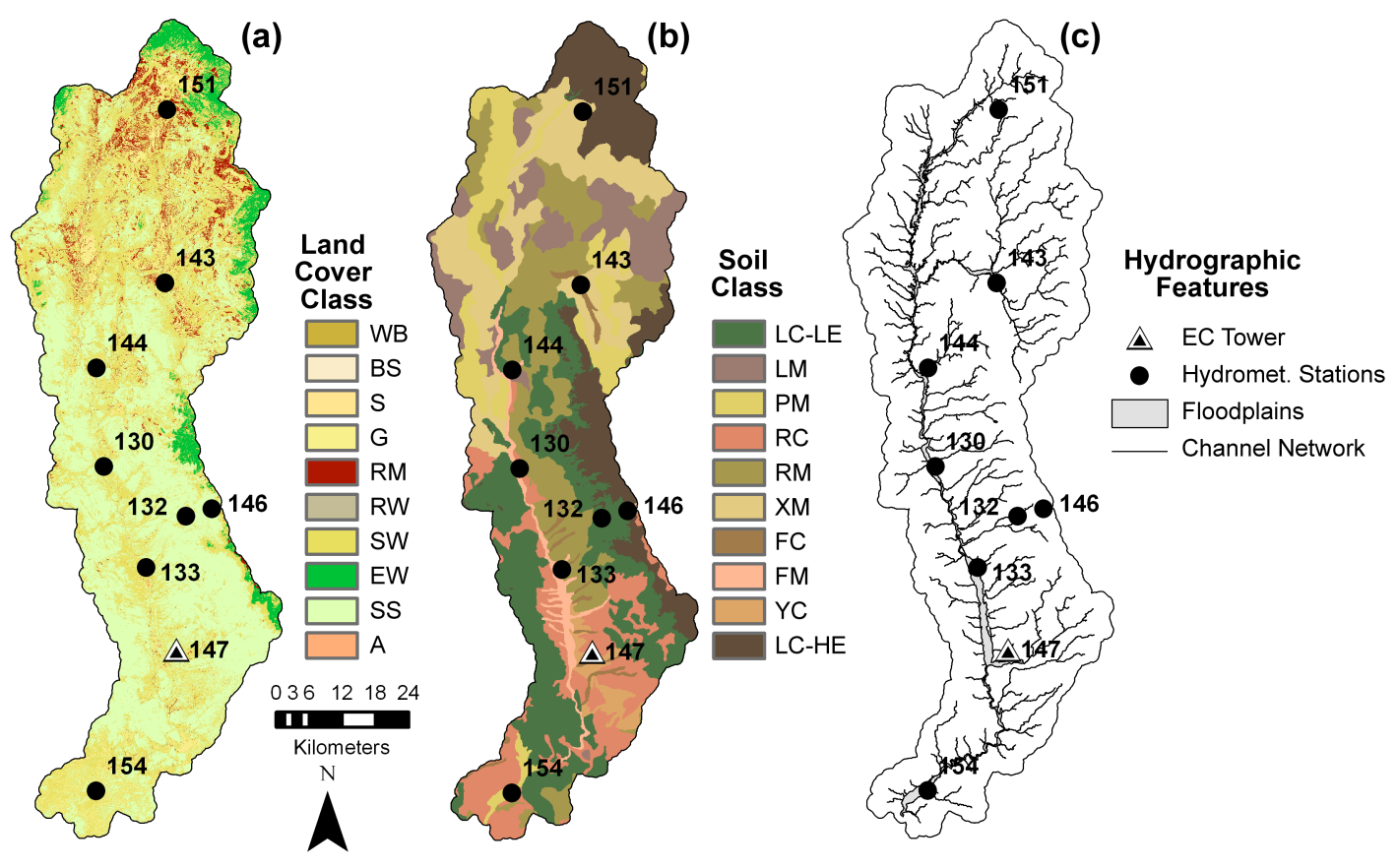

Fig. 2. (a) Land cover and (b) soil class maps of the RSM basin with location of the stations used

4 for testing the hydrologic model. (c) Channel network and floodplain boundaries represented in

5 the model. Acronyms of the soil and land cover classes are described in Table 1. 

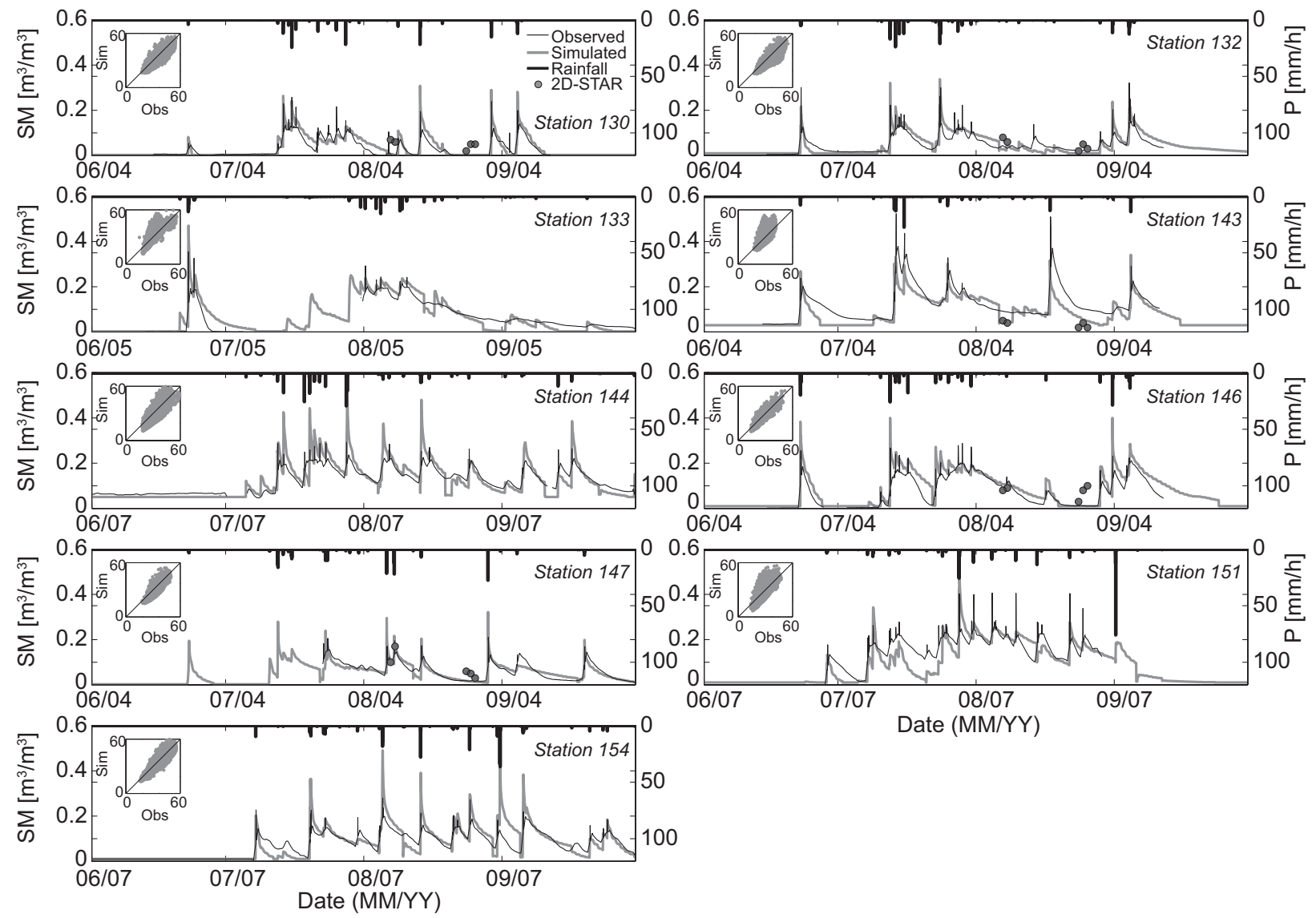

2 Fig. 3. Comparison of observed and simulated surface (top $5 \mathrm{~cm}$ ) SM at individual stations,

3 along with 2D-STAR retrievals at the co-located pixel (where available). Insets show scatterplots

4 between observed and simulated LST $\left({ }^{\circ} \mathrm{C}\right)$. Data gaps are due to missing observations or poor

5 data quality. 
(a) SM - 08/08/04

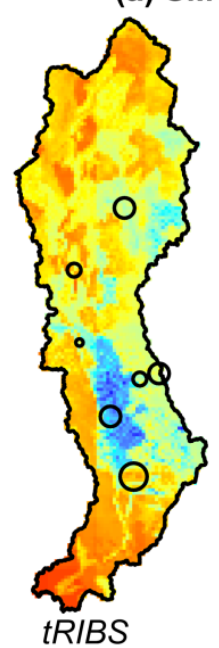

(c) LST - 08/08/04

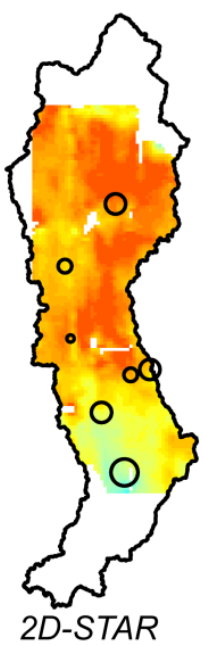

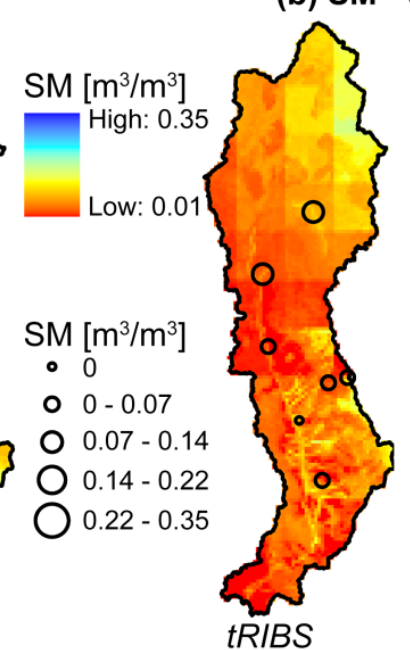

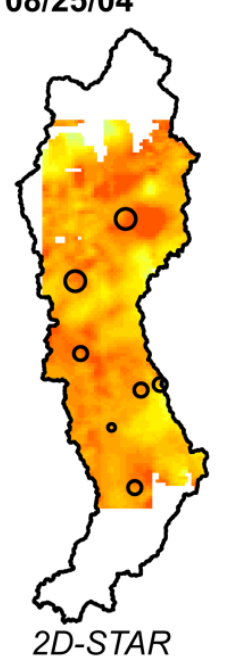

(d) LST - 08/25/04
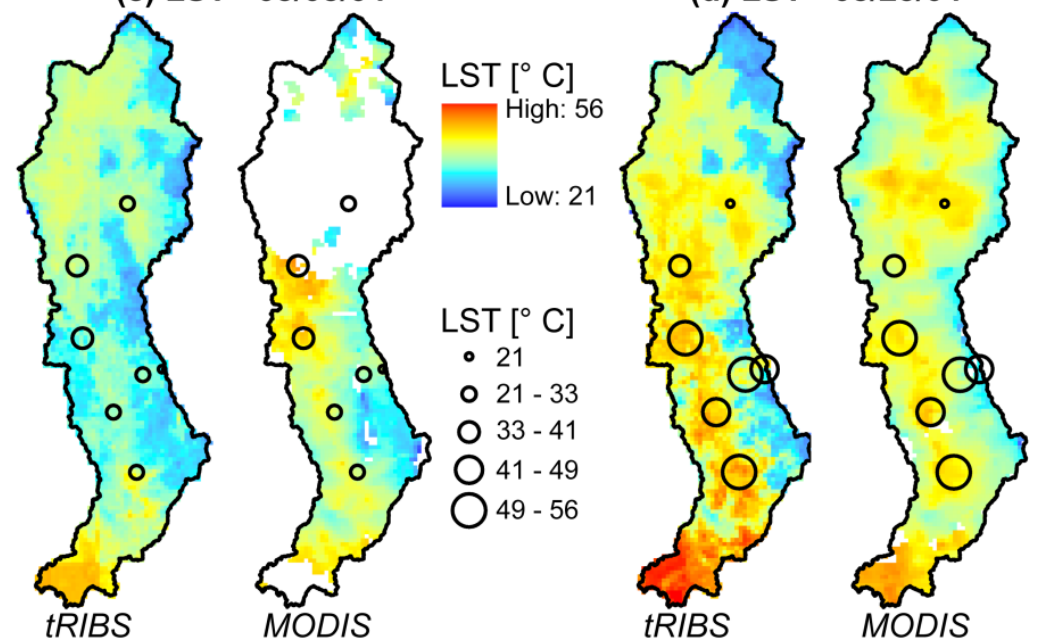

Fig. 4. (a, b) Comparison of spatial patterns of simulated and retrieved (2D-STAR) surface (top 5 cm) SM on 8 and 25 August 2004. (c, d) Comparison of spatial patterns of simulated and

5 estimated (MODIS) LST on the same days. Model outputs are for the overpass times and are

6 resampled at same resolution ( $800 \mathrm{~m}$ for 2D-STAR and $1000 \mathrm{~m}$ for MODIS). White areas

7 represent missing data. Circles of different size depict the surface SM and LST measured by 8 individual stations at coincident times. 
2 Fig. 5. Basin-averaged time series of (a) daily total $P$, (b) daily average NDVI, (c) daily average

3 surface (top $5 \mathrm{~cm}$ ) and root zone (top $1 \mathrm{~m}$ ) SM, (d) daily average LST, (e) daily total ET, and (f)

4 daily total Q at the outlet (expressed as depth to facilitate comparison with other fluxes). Summer

5 (1 July to 30 September) and winter (1 December to 28 February) seasons are indicated during

6 the simulation period from 1 January 2004 to 31 December 2010. 
(a) P - Summer

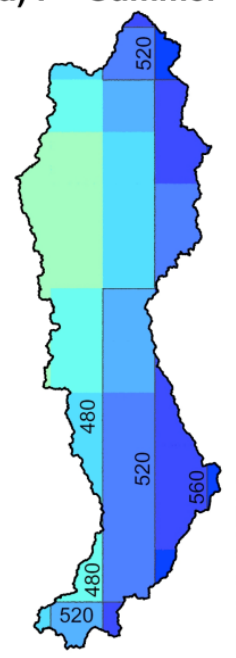

(b) P - Winter

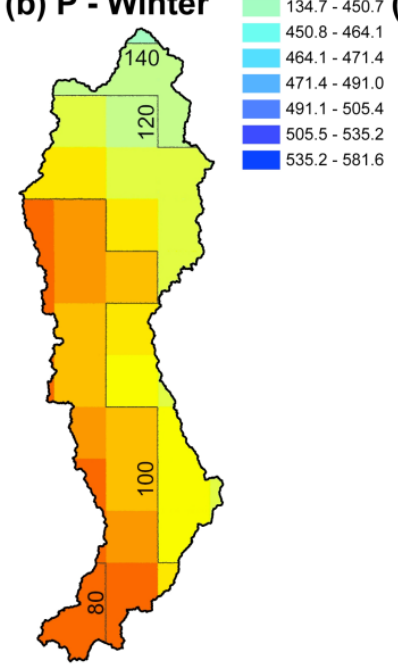

(c) SM - Summer

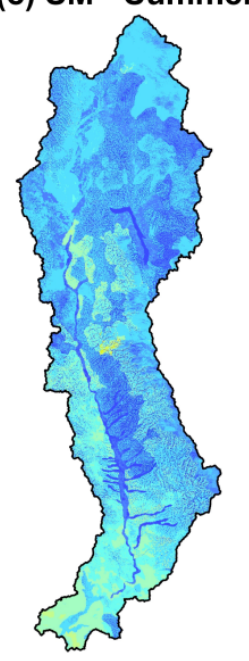

(d) SM - Winter

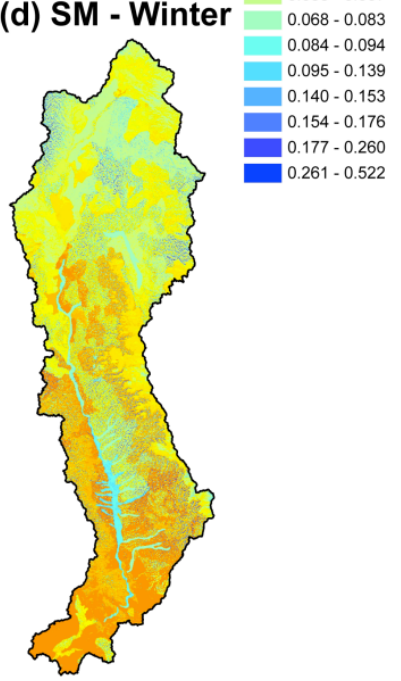

(e) ET - Summer

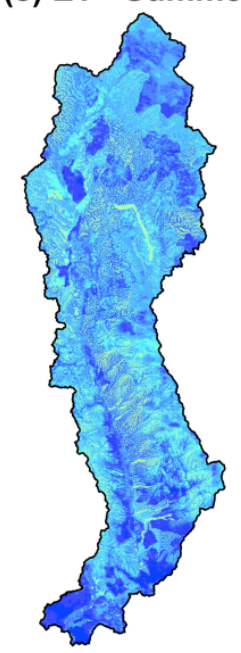

(f) ET - Winter

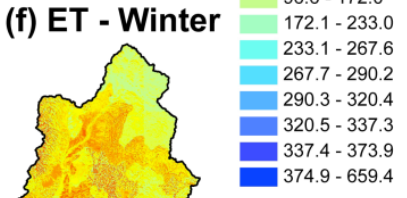


1

2

3

4

5

6

8

9

10

11

12

13

14

15

16

17

18

19

20

21

22

23

24

25

50

51

52

53

54

55

56

57

58

59

60

61

62

63 (a) $\mathrm{P}$

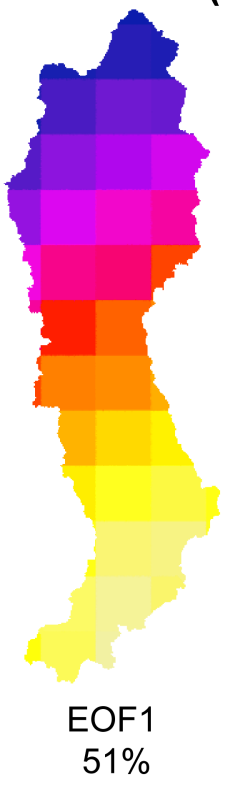

1

3 Fig. 7. First two EOFs of (a) $\mathrm{P}$ and (b) VF at the monthly scale, with the percentage of the

4 explained variance indicated. (b) VF

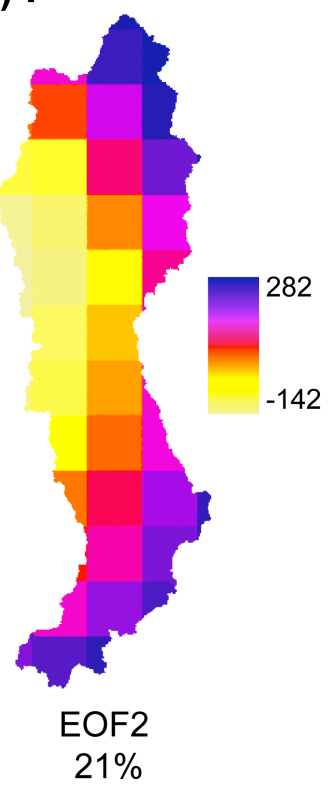

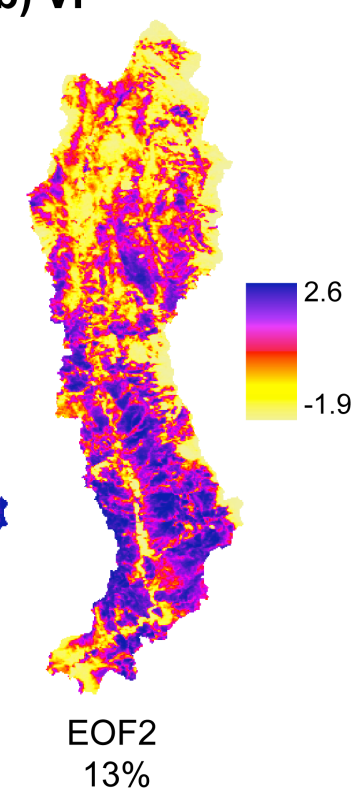

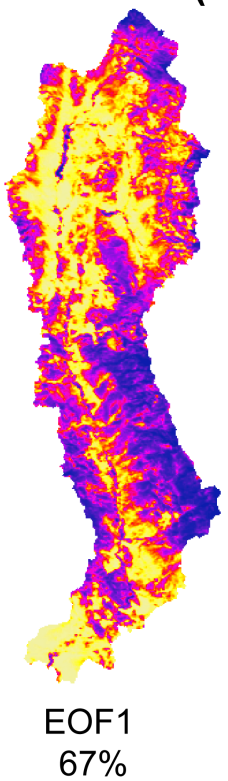

$13 \%$ explained variance indicated. 

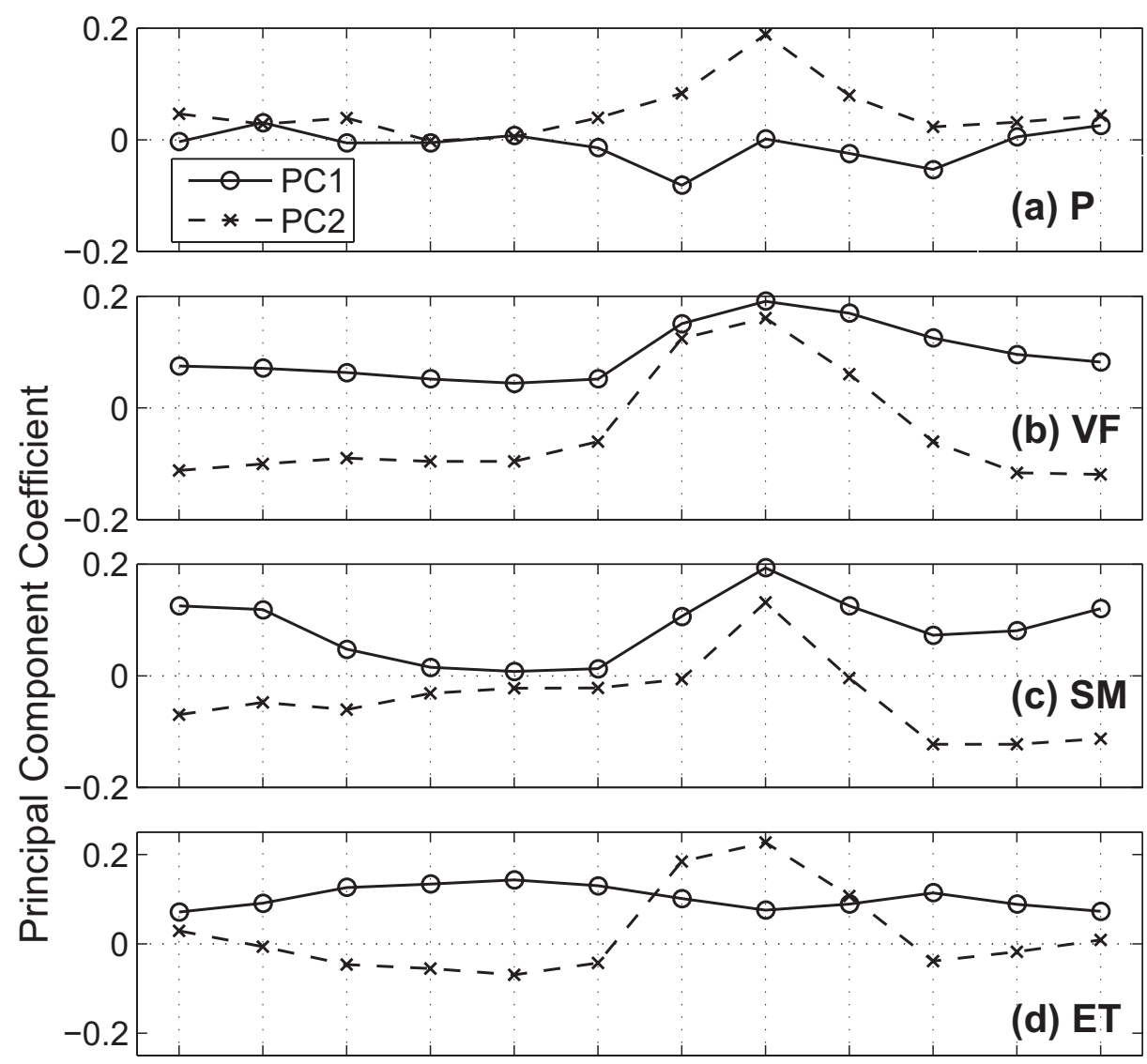

2 Fig. 8. Time series of the monthly averaged PCs associated with the first two EOFs at the

3 monthly scale of (a) P, (b) VF, (c) surface SM, (d) ET and (e) Q. 
(a) SM

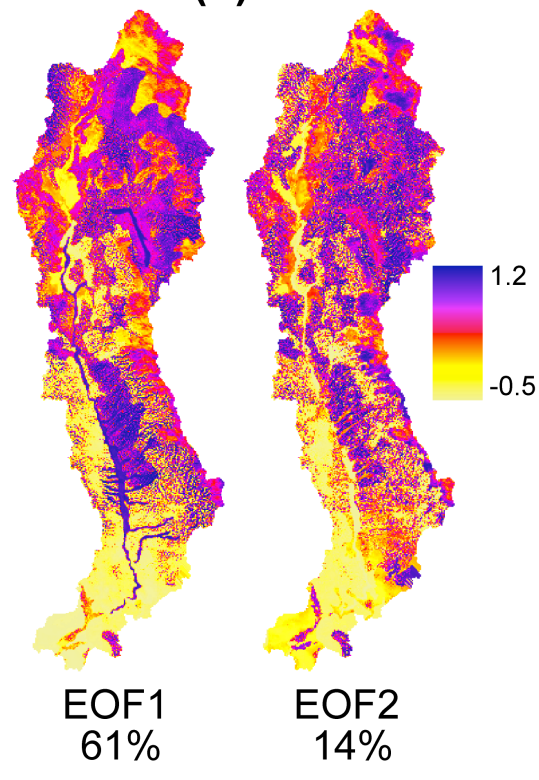

(b) ET

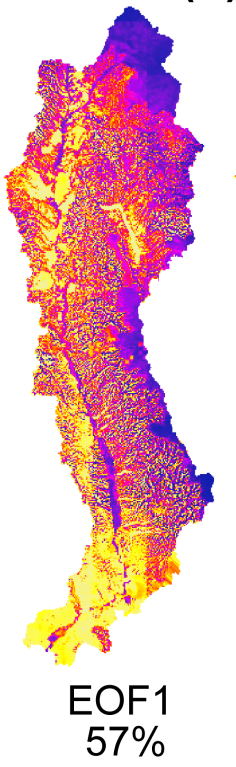

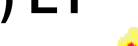

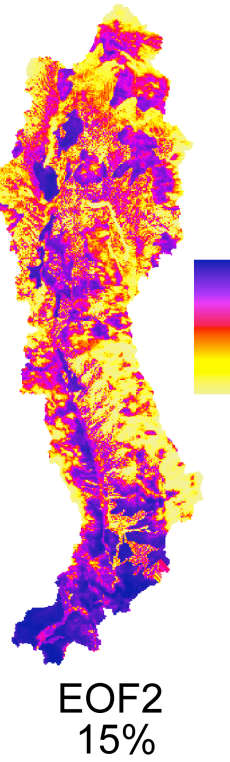

(c) $\mathbf{Q}$

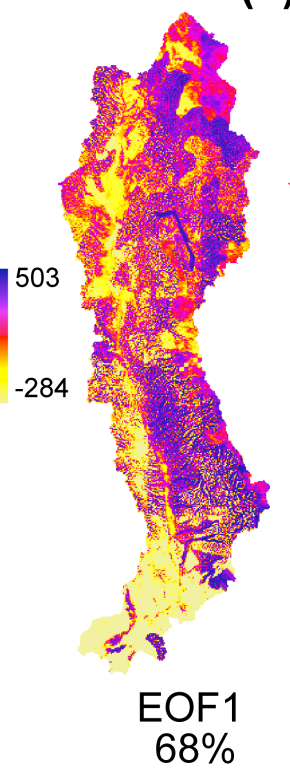

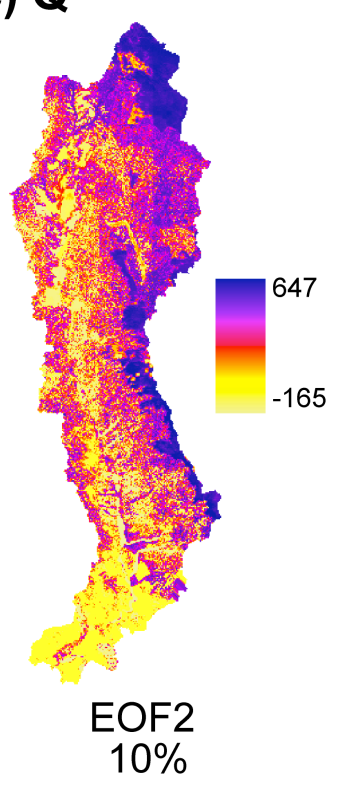

Fig. 9. Same as Fig. 7, but for (a) surface SM, (b) ET and (c) Q. 

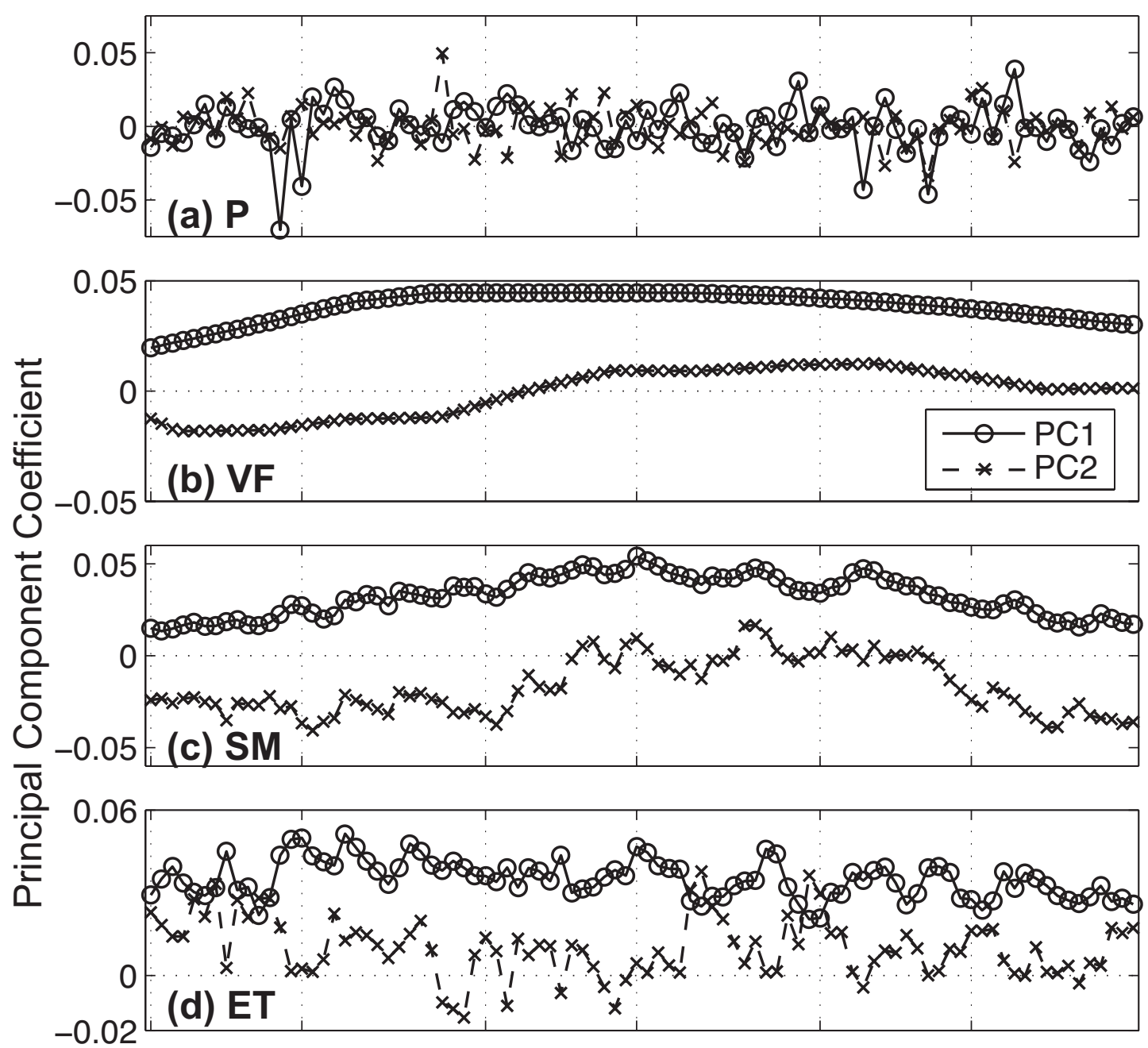

2

3 Fig. 10. Time series of the daily averaged PCs associated with the first two EOFs at the daily

4 scale in summer for (a) P, (b) VF, (c) surface SM, (d) ET and (e) Q.

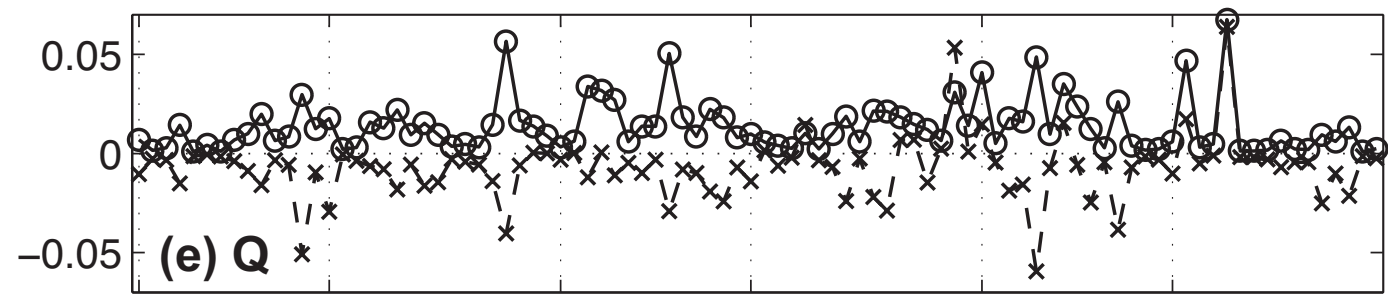

\section{7/01 07/15 08/01 08/15 09/01 \\ Date (MM/DD)}



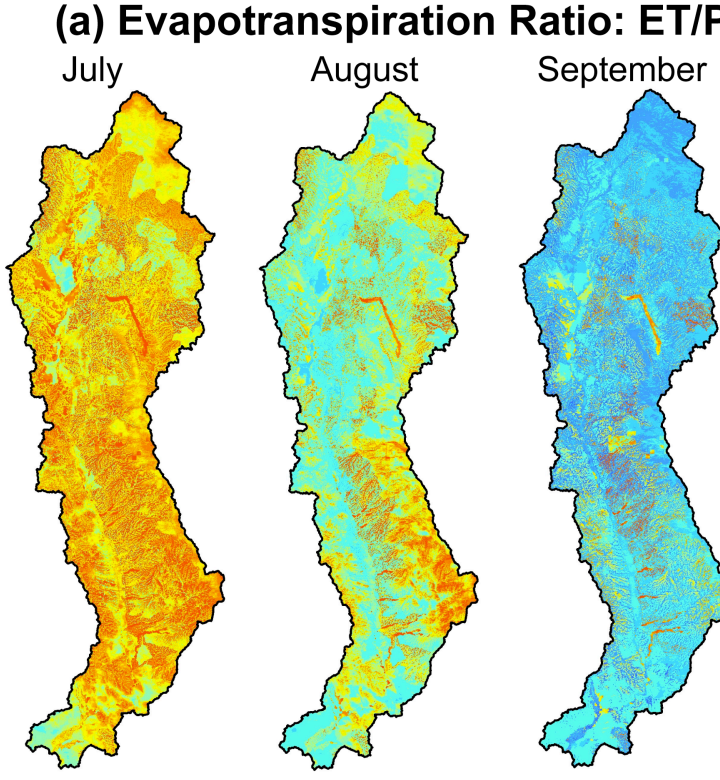

(b) Runoff Ratio: Q/P
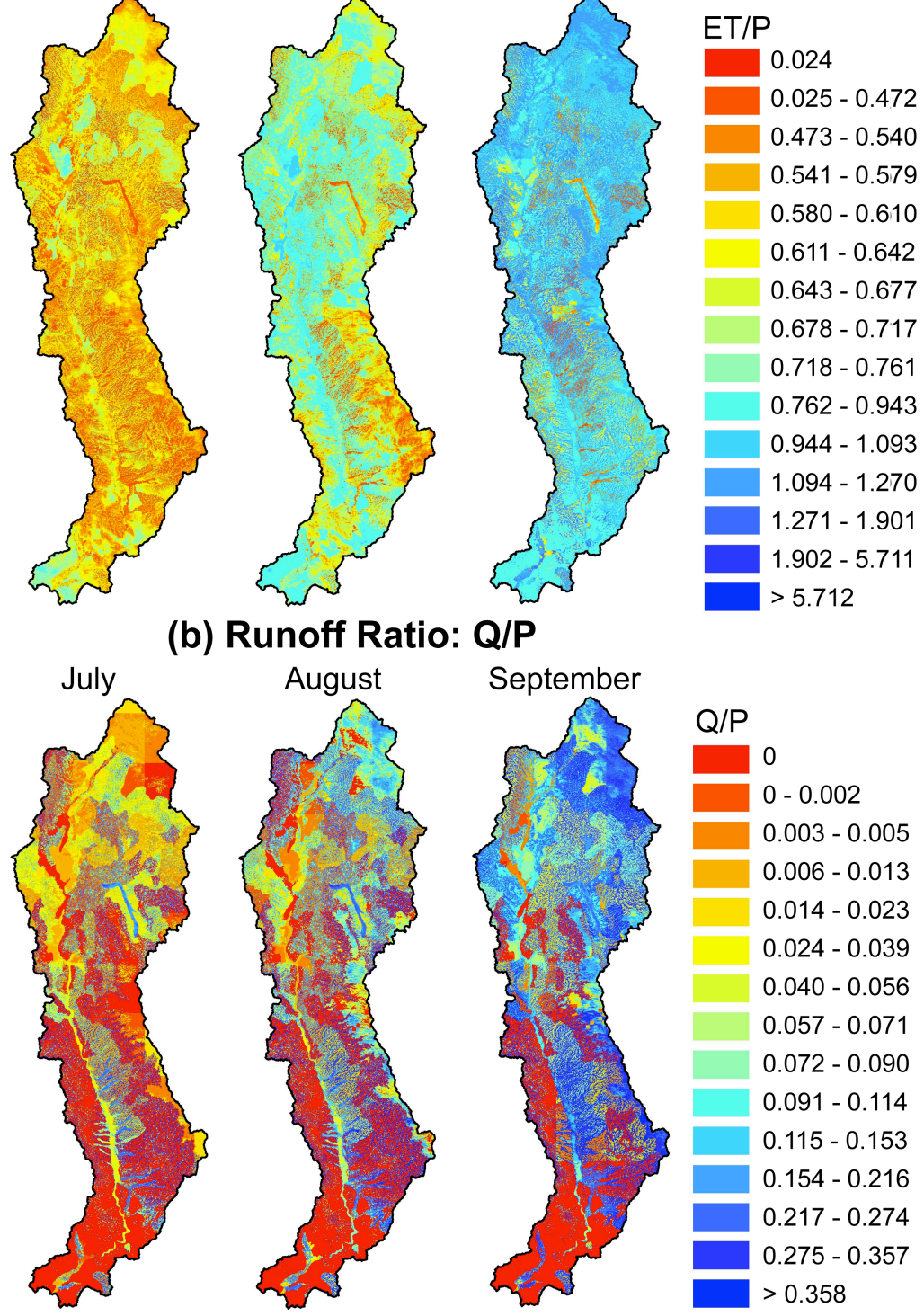

2 Fig. 11. Spatial distribution of (a) evapotranspiration ratio (ET/P) and (b) runoff ratio $(\mathrm{Q} / \mathrm{P})$

3 averaged over the summer months in the simulation. 


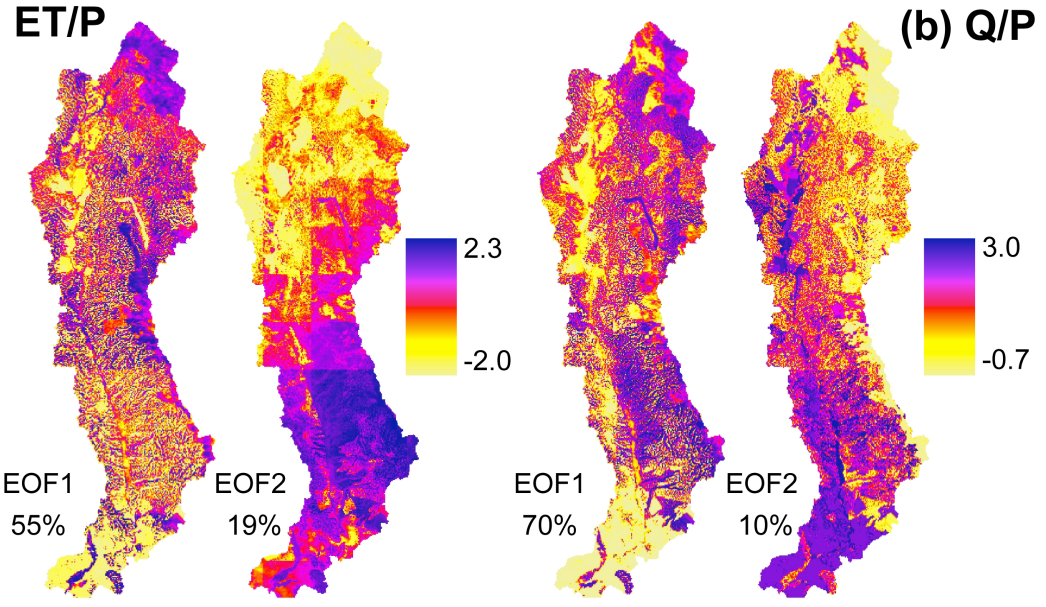

(c) ET/P

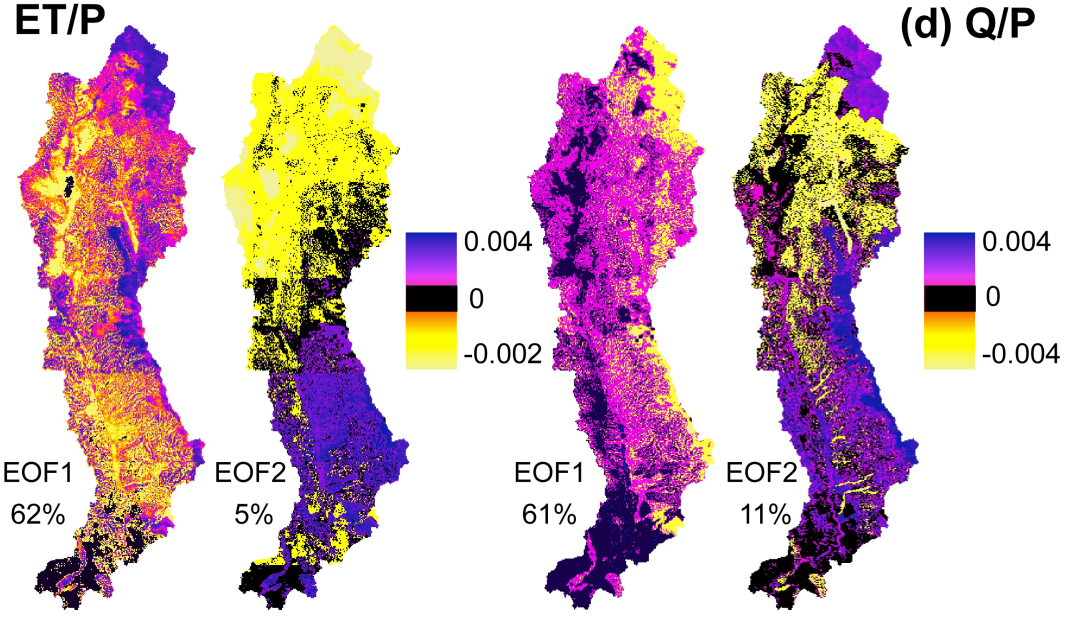

1

3 Fig. 12. First two EOFs of ET/P and $Q / P$ at the monthly scale for the spatial $(a, b)$ and temporal 4 (c, d) anomalies, with the percentage of explained variance indicated. 


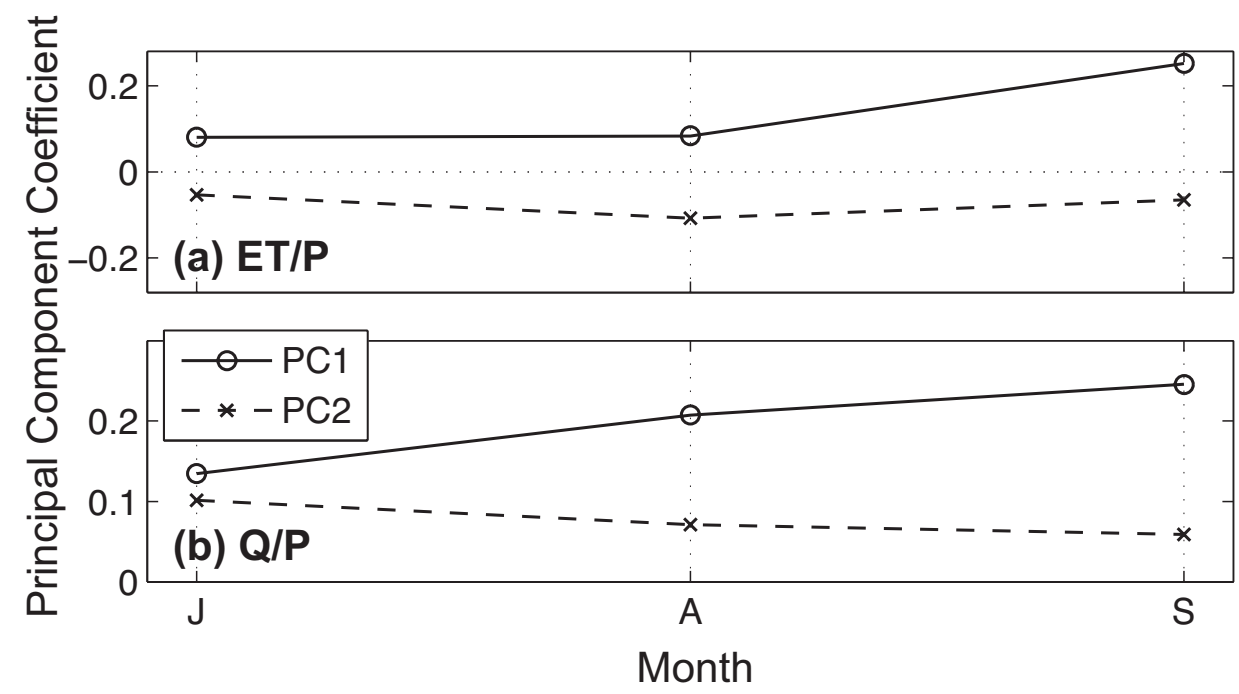

2 Fig. 13. Time series of the monthly averaged PCs associated with the first two EOFs at the 3 monthly scale in the summer for (a) ET/P and (b) Q/P. 